\title{
Flood Frequency Analysis of Chenab River for Predicting Peak Flows during Late Monsoon Period
}

\author{
Sonia Ijaz*, Qudsia Hameed, Aiza Ahsan, Muhammad Atif Butt \\ Centre of GIS Punjab University College of Information Technology, Lahore, Pakistan \\ Email: *soniarabia8@yahoo.com
}

How to cite this paper: Ijaz, S., Hameed, Q., Ahsan, A. and Butt, M.A. (2019) Flood Frequency Analysis of Chenab River for Predicting Peak Flows during Late Monsoon Period. Advances in Remote Sensing, 8, 1-29.

https://doi.org/10.4236/ars.2019.81001

Received: December 29, 2018

Accepted: March 8, 2019

Published: March 11, 2019

Copyright $\odot 2019$ by author(s) and Scientific Research Publishing Inc. This work is licensed under the Creative Commons Attribution International License (CC BY 4.0).

http://creativecommons.org/licenses/by/4.0/

\begin{abstract}
The River Chenab is one of the main western rivers of the Indus River system in Pakistan, which undergoes intensive inundation almost every year during the late monsoon period. The present study performs flood frequency analyses for the river basin as well as simulates different levels of water flow in the system to speculate all kinds of inundation under different scenarios, i.e., to predict flood hazard and flood extended areas. Flood frequency analyses were performed at MARALA Headworks to Khanki Headworks. Data were collected from the Punjab Irrigation Department, Pakistan and from USGS and ASTER GDEM. The peak discharge of MARALA Headworks had been analyzed for 25 years. The preprocessing was performed in HEC Geo-RAS after preprocessing model run in HEC-RAS. After analysis the data were exported in HEC-RAS to ARCMAP to generate a floodplain and inundation map. Our analysis generated the result that different areas would be under water in different return periods. Flood hazards maps for different return periods 10, 20, 50 and 100 years were conducted using annual peaks flow of 35 years from 1980 to 2016. The maximum discharges at up and down stream for different periods were obtained using Gumbel distribution model results which showed that different areas were predicted under water in different return periods and affected areas after five years' return period.
\end{abstract}

\section{Keywords}

ASTER GDEM, HEC Geo-RAS, ARCMAP, Gumbel Distribution Model

\section{Introduction}

Flooding in arid mountainous regions leads to serious catastrophic outcomes 
that affect a country's infrastructure. The governing factors are generally intensive rainfall and/or glacier melting [1] [2]. On a global scale, the impact of these extreme events is not even, and particularly developing countries in South Asia face higher damages compared to the rest of the world [3] [4] [5]. The fundamental reason behind these losses is lack of adaptation resources, i.e., social, technical, and engineering facilities [6].

It is also important to drive an evaluation procedure to determine its predictive results [7]. The flood recovery cycle is used to re-establish flood attack area [8]. River floods often attack the river bank and take away huge farmland [9]. However, deposits also have disorderly effects on adjacent crops, which may increase crop fertility, or for a longer period of time to completely destroy farmland, as if sand were deposited as [10]. Pakistan is situated in a region which is highly prone to climate changes [11] possessing most of the rivers being shared by India as an upper riparian. River Chenab, being one of the three major western rivers, has an important contribution in water resources of Pakistan [12].

In the recent flooding of Pakistan in 2014, about four feet of sand was observed in the crop area of the Hafizabad region. Farmers were getting farmland from sediments, but still could not determine how much land was recovering from sand. The analysis and forecasting tools for agricultural development planning are observed before the results of various evolution decisions GIS data can be used [13]. Timely identification of flood affected areas can save living things and funds through early caution. Today GIS, GPS and remote sensing technologies prove helpful in that flood disaster managers develop exact flood maps at a lower cost and also provide hardware and software packages [14].

There are many frequency models which are now used for determining hydrologic frequency of flood. The probabilistic model relies on the use of existing data to forecast future scenario and deterministic model relies on different physical parameters to bring out the result and verify it with the existing data to develop a best fit model. Probabilistic approach is commonly practiced in hydrology [15]. Within probabilistic models, the two most popular are Gumbel maximum value and Log Pearson type III distribution.

The parameter estimation is done by using many ways, viz. by maximum likelihood estimators, method of moments (MOM) or by methods of L-Moments. L-Moments are based on probability-weighted moments (PWMs), for the data arranged in ascending order. The MOM technique is good for limited range of parameters, whereas L-Moments can be more widely used, and are unbiased [16].

Geographic Information System (GIS) and Remote Sensing are frequently and effectively used for flood hazard forecasting and mapping [17] [18]. Similarly, the applications of hydrodynamic models are also quite obvious in flood management studies and are used as a decision support tool. However, these models require proper characterization of the channel and adjacent floodplain. HEC-Geo RAS, an extension used in the ArcGIS, to process geospatial data for use with the Hydrological Engineering Centre River Analysis System (HEC-RAS). HEC-RAS is 
a 1D hydrodynamic model, used to simulate river flood phenomena and the results can be presented in a geospatial format [19] applied HEC-RAS one-dimensional model in combination with the ASTER DEM for flood modelling in the Kalpani river reach in Khyber Pakhtunkhwa, Pakistan. Application of HEC-RAS for flood forecasting in perched river in Lingshi County, Shanxi Province of China [20]. Similarly, [21] also utilizes a hybrid approach of HEC-RAS and GIS to determine vulnerable localities along a $5 \mathrm{~km}$ long Nike river channel in northern Iran. With the developments in integrating capabilities of Remote Sensing (RS) (satellite imagery, Digital Elevation Models (DEMs)), GIS and Hydrodynamic modelling have provided opportunities for quantitative analysis of flood events, from local to regional scales [22].

[23] developed a simulation model for real time flood-control operation of river-reservoirs systems. Shahid et al. conducted in the Chenab River catchment, Pakistan, to develop and evaluate a hydrologic model using HEC-HMS for predicting flows based on TRMM rainfall data and found that capturing the hydrologic response of the catchment due to rainfall events.

Hydrologic engineering center-river analysis system (HEC-RAS), which was developed by the US army corps of engineers, has been applied extensively in calculating the hydraulic characteristics of rivers [24]. HEC-RAS calculates one-dimensional steady and unsteady flows, and the model equations are also described by [25].

The present study focused on the Chenab River is the main river in India and Pakistan. It is formed in the upper part of the Himalayas in the Latin America and the Kapur region of Jammu and Kashmir, and enters the plains of Punjab, Pakistan. According to the Indus River Treaty, Chenab's waters are allocated to Pakistan. The major objectives of the present study are flooding frequency analysis by hydrodynamic analyze the river, simulate different levels of water and water flow at different times and determine flood hazard, flood extended areas. This study will also be beneficial for flood extent prediction for future perspective. It also enables us to draw plan for mitigation and damages control.

\section{Methodology}

\subsection{Study Area}

First, Study area coordinates are Left 73.23455477863293, Top 33.25213418273533, and Bottom 31.62131683314346dd, Right 75.5195246098708dd as shown in Figure 1.

Current Study comprises over 42 cross sections will be used to map the interval of each important location along the $96 \mathrm{~km}$ river length. In the present study gives insight about the river modelling and assessment using the HEC-RAS model. Moreover the river's fluid dynamics with the different levels of water and water flow in different periods helps to draw extent of river and damage assessment. All the results will be calculated and drawn from the ArcGIS and HEC-RAS software for hydrodynamic modelling. In order to apply the HEC-RAS model for the study area, the following necessary data sets will be set 


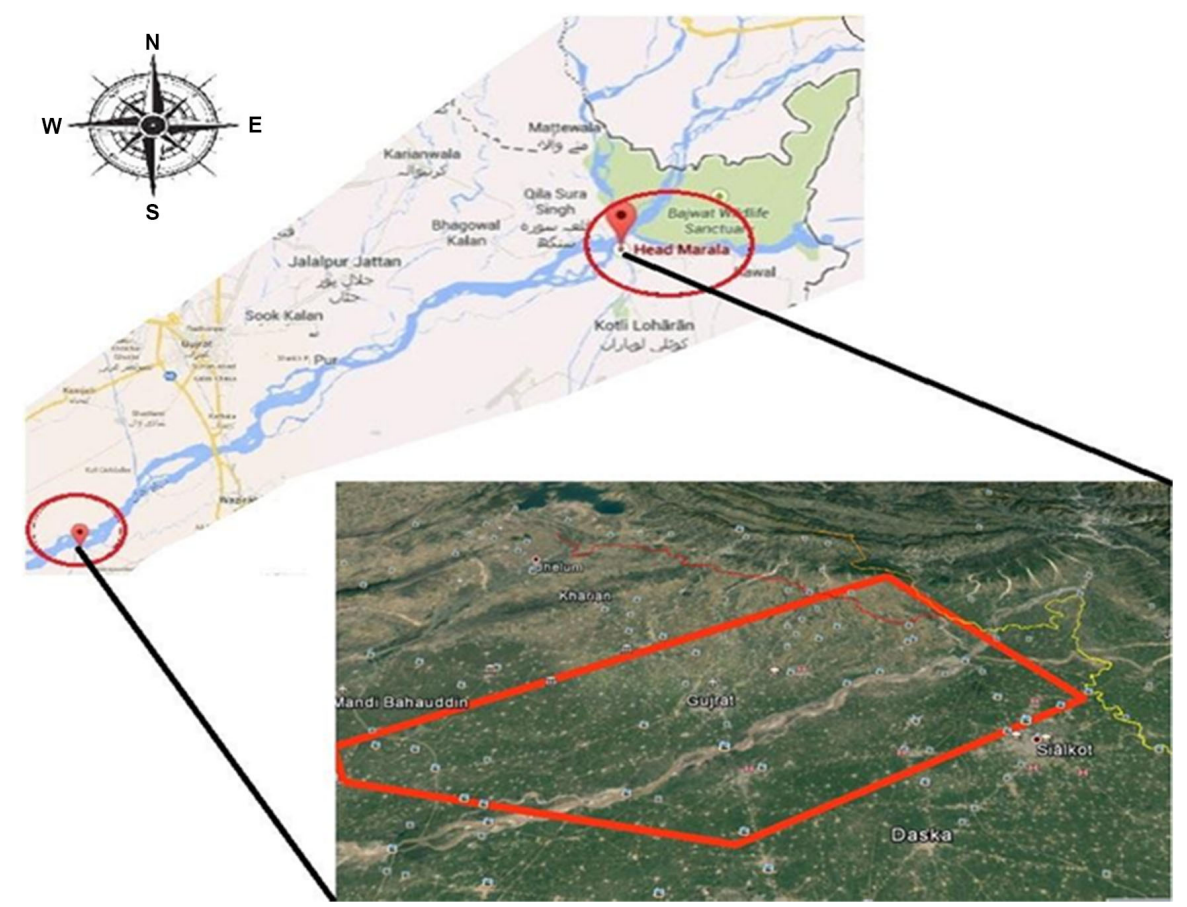

Figure 1. Sialkot Area.

up to prepare and extract the geometric data and Manning's roughness at the flow cross-section and define the flow discharge input data method [26]. The whole process is explained in term of flow diagram in Figure 2.

\subsection{Data Sources}

Data collection process involves mainly from the secondary source. The study requires spatial and hydrological data, channel geometry, boundary conditions, and channel resistance for flow simulation through HEC-RAS. Organization addressed for data are an Irrigation department of Pakistan, Punjab, Lahore and Primary data collection from USGS and ASTER GDEM.

\subsection{Tools and Technologies Used for Modeling}

The purpose of this study is to use HEC-GEO HMS model to simulate and evaluate the flood in Chen cloth in Hebei Province, to model and analyze the river hydrodynamics, and to simulate the different water level and water flow in different periods. HEC-GEO HMS4.2 Software applied for hydrodynamic modelling. In order to apply the HEC GEO HMS model to the study area, the following necessary data sets will be set up to prepare and extract geometric data and Manning's rough coefficients in the stream and define the flow input data method.

\subsection{DEM Data}

The Digital Elevation Model (DEM) is a digital model or 3D representation of terrain surfaces that are typically used to create planets (including earth), lunar 


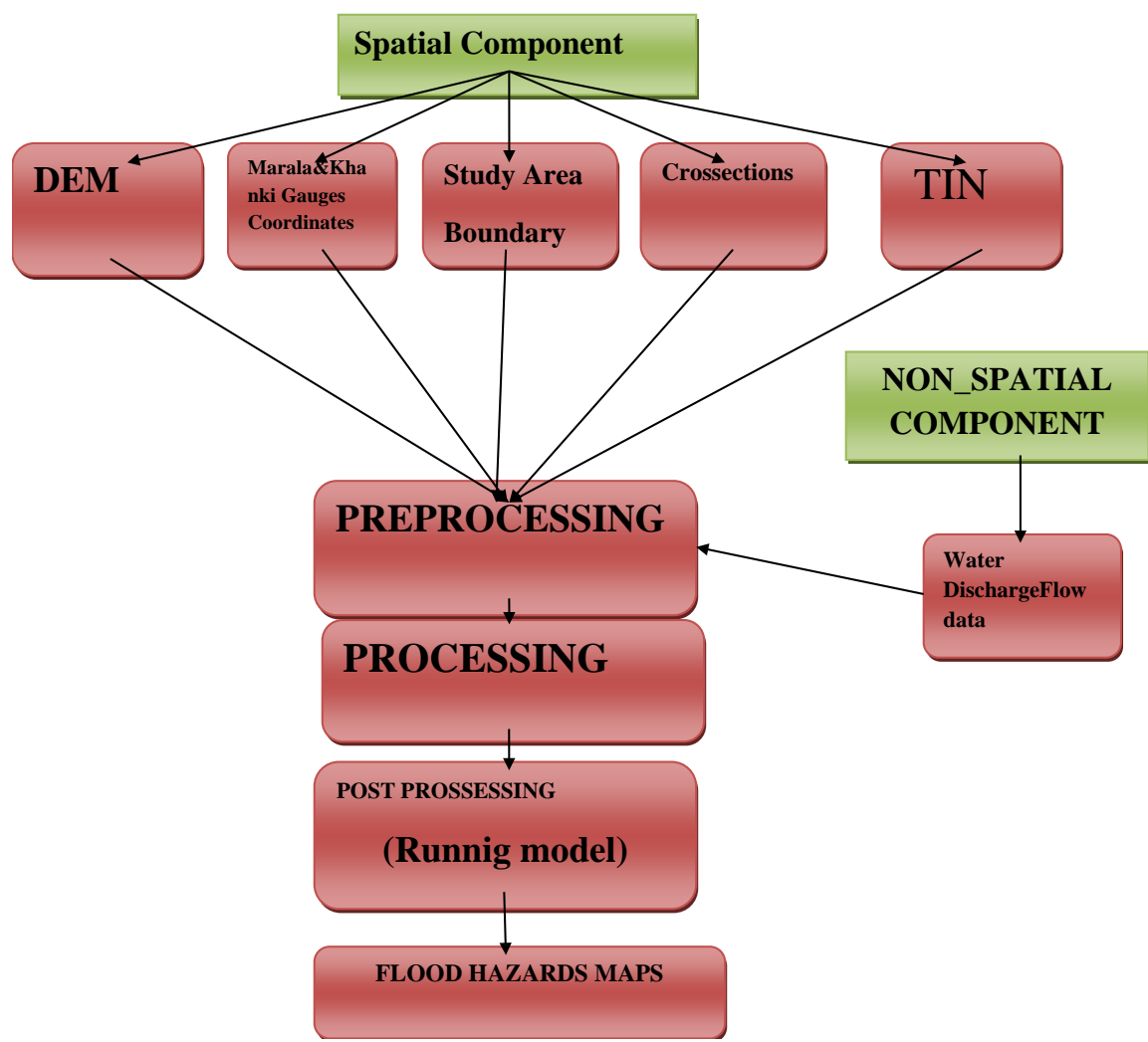

Figure 2. Flow diagram.

or asteroids from terrain elevation data as expressed in Figure 3. DEM can be expressed as a raster (square grid, also known as elevation, when it represents elevation) or vector-based triangular irregular network (TIN). The TIN DEM dataset is also called the main (measurement) DEM. Surfaces are usually modelled with raster datasets. Rasters are cell matrices, also known as pixels, organized in rows and columns, covering some parts of the world (even the whole world). Each cell in the matrix represents a square of the unit area and contains a value that is the measure or estimate of the position.

\subsection{Flood Frequency Analysis}

Flood frequency analyses are used to predict design floods along a river. The technique includes using observed yearly peak flow discharge data to calculate statistical information. Rated curve (or stage-discharge curve) displays the relationship between the stage (water level) and the displacement of the point on the flow path. The flood frequency curve is a graph showing the relationship between the flood magnitude and the repeated interval of the specified location. Different formulas (e.g. Gumble Formula, Hazen Formula, Blom Formula etc.) were applied and different curves were obtained as shown in Figures 4.1-4.7.

Best fitted formula was only Gumbel formula, as shown in Figure 4.6. It proves that our data are consistent. We find the peak values of flow after 2 years, 5 years, 10 years, 15 years and 100 years return period and results are given below: 


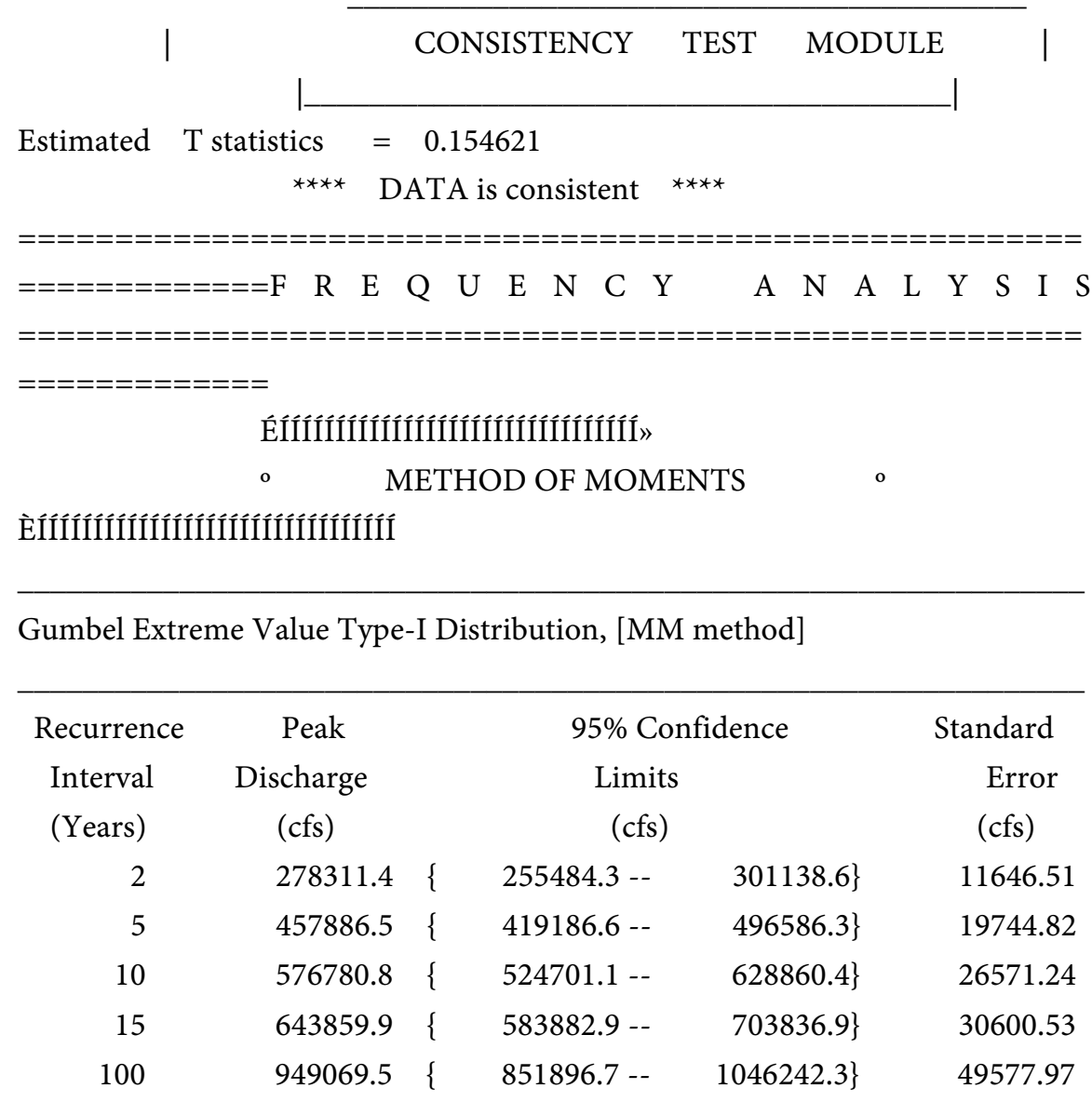

Gumbel Extreme Value Type-I Distribution, [MM method]

\begin{tabular}{rcrcrc}
\hline $\begin{array}{c}\text { Recurrence } \\
\text { Interval } \\
\text { (Years) }\end{array}$ & $\begin{array}{c}\text { Peak } \\
\text { Discharge } \\
(\mathrm{cfs})\end{array}$ & \multicolumn{3}{c}{$\begin{array}{c}\text { 95\% Confidence } \\
\text { Limits }\end{array}$} & $\begin{array}{c}\text { Standard } \\
\text { Error }\end{array}$ \\
2 & 278311.4 & \{ & $255484.3--$ & $301138.6\}$ & 11646.51 \\
5 & 457886.5 & \{ & $419186.6--$ & $496586.3\}$ & 19744.82 \\
10 & 576780.8 & \{ & $524701.1--$ & $628860.4\}$ & 26571.24 \\
15 & 643859.9 & \{ & $583882.9--$ & $703836.9\}$ & 30600.53 \\
100 & 949069.5 & \{ & $851896.7--$ & $1046242.3\}$ & 49577.97
\end{tabular}

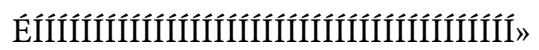

- METHOD OF MAXIMUM LIKELIHOOD o

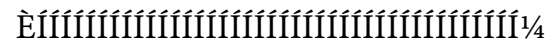

Gumbel Extreme Value Type-I Distribution, [ML method] 


\begin{tabular}{cccccc}
$\begin{array}{c}\text { Recurrence } \\
\text { Interval } \\
\text { (Years) }\end{array}$ & $\begin{array}{c}\text { Peak } \\
\text { Discharge } \\
(\mathrm{cfs})\end{array}$ & \multicolumn{3}{c}{$\begin{array}{c}\text { 95\% Confidence } \\
\text { Limits } \\
(\mathrm{cfs})\end{array}$} & $\begin{array}{c}\text { Standard } \\
\text { Error } \\
(\mathrm{cfs})\end{array}$ \\
2 & 278395.0 & \{ & $253172.4--$ & $303617.7\}$ & 12868.69 \\
5 & 470840.1 & \{ & $432130.3--$ & $509549.9\}$ & 19749.88 \\
10 & 598255.5 & \{ & $548597.6--$ & $647913.4\}$ & 25335.66 \\
15 & 670142.2 & \{ & $614007.1--$ & $726277.3\}$ & 28640.36 \\
100 & 997226.0 & \{ & $910399.8--$ & $1084052.3\}$ & 44299.09
\end{tabular}

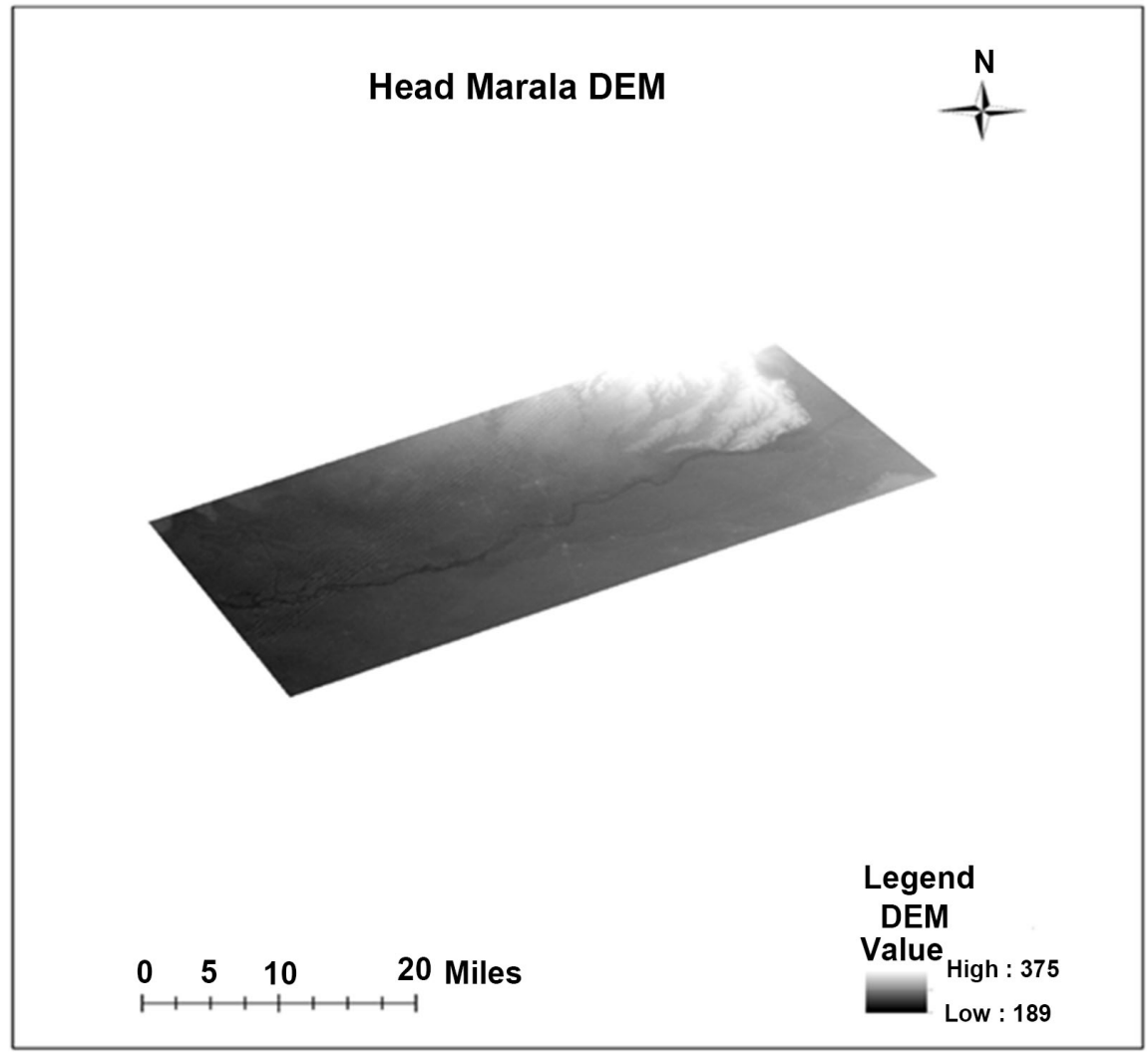

Figure 3. DEM data.

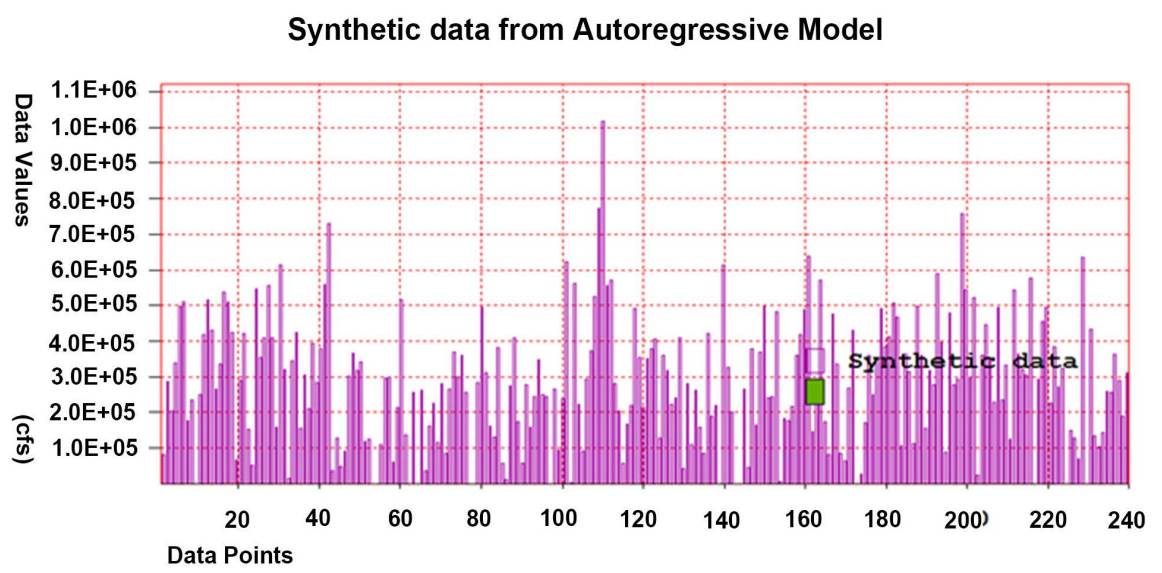

Figure 4.1. Autoregressive model. 


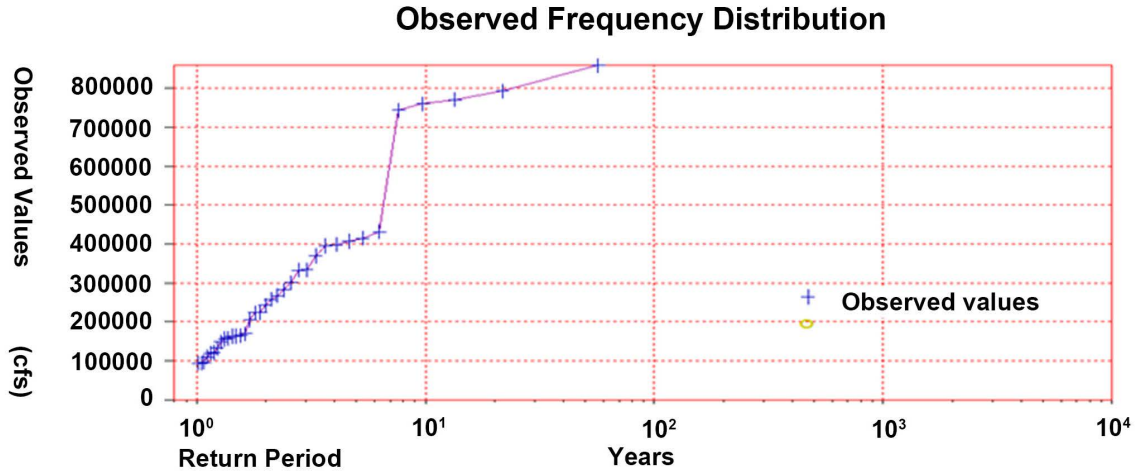

Figure 4.2. Blom formula.

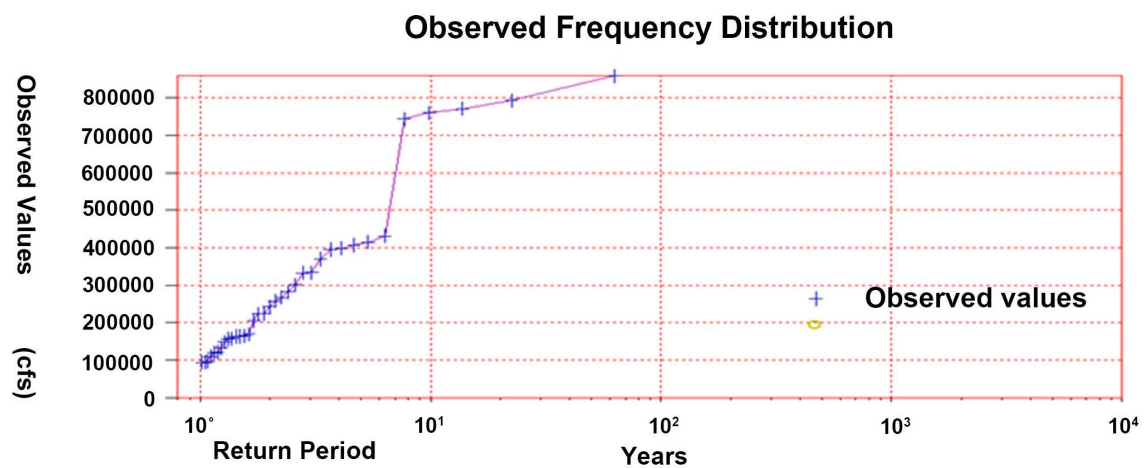

Figure 4.3. Gingorton formula.

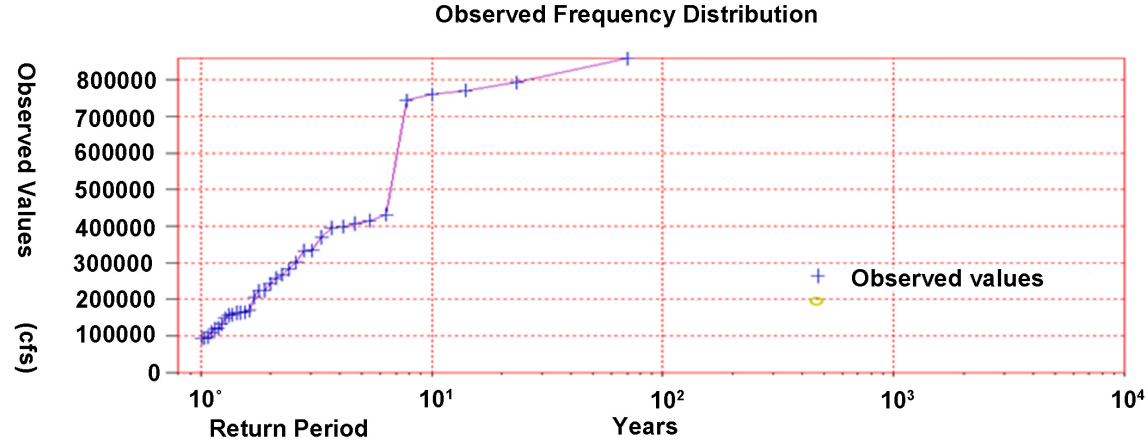

Figure 4.4. Hazen formula.

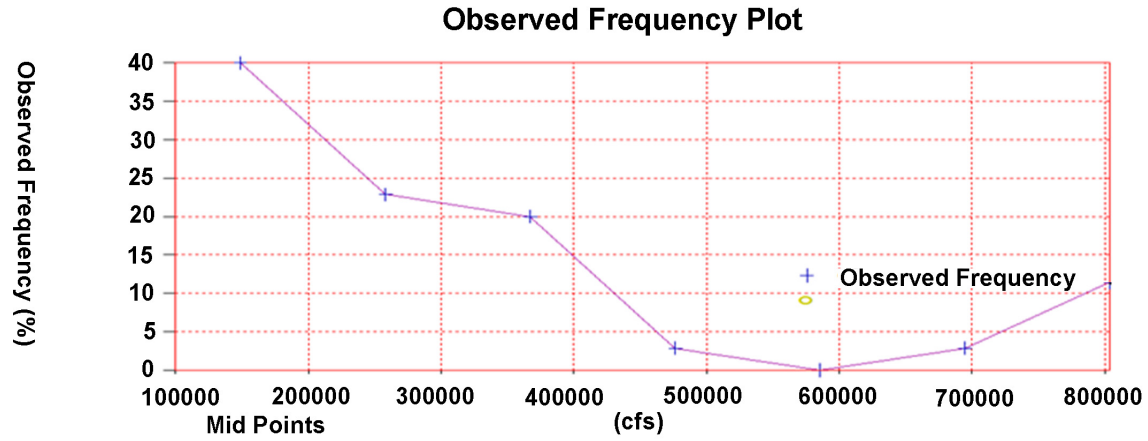

Figure 4.5. Relative frequency formula. 
Gumbel Extreme Value Type-I [Method of Moments]

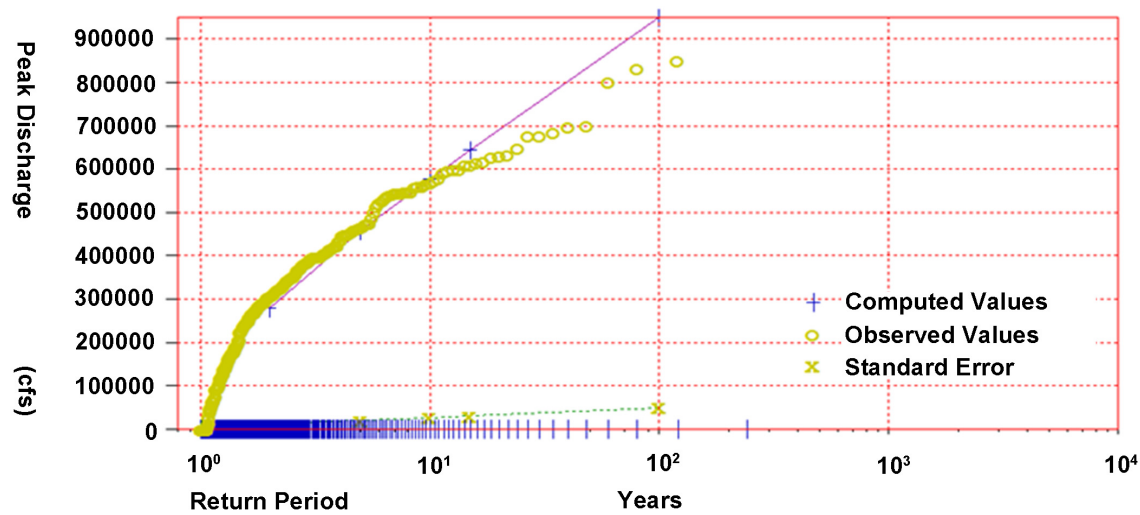

Figure 4.6. Gumbel formula.

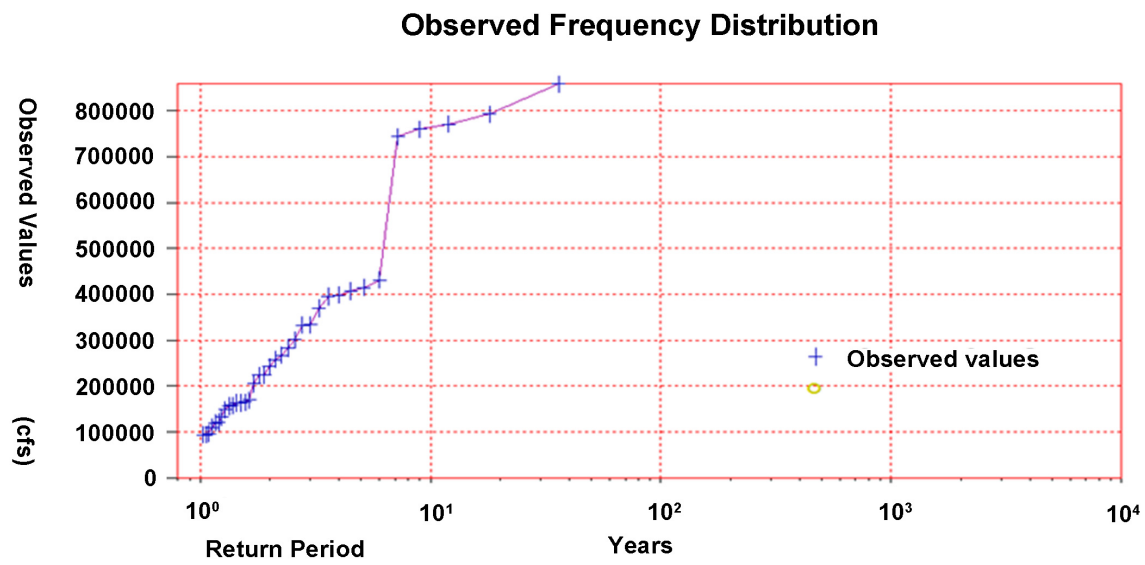

Figure 4.7. Wiebell formula.

\subsection{Cross-Section}

The spacing is very close to the cross-section should be shown in each super bank and channel similar to the flow.

\subsection{Cross-Section-Requirement}

Cross sections are required at representative location along a river reach where:

$>$ Slope changes.

$>$ Cross section shape changes.

$>$ Roughness changes.

$>$ A levee starts and end.

$>$ Bridge, Culverts, Weir and other control structures.

$>$ Junction/Confluence.

$>$ Where abrupt changes occur, several cross section should be used to describe the change regardless of the distance.

$>$ Up to 500 ground points can be used to describe the cross section.

>HEC-RAS takes into account Cross section data with Distance taken on (X-axis) 
\& Elevation on (Y-Axis).

$>$ Cross section should be defined perpendicular to the direction of flow as shown in Figure 5.

\subsection{Processing}

\section{Required Data}

The essential dataset required for HEC-Geo RAS, HEC-RAS and Arc GIS DEM, TIN, River Boundary of study area, Gauges Data

Required softwares are Arc GIS, DFW, HEC-RAS latest version, HEC-Geo RAS (Extension) with ArcGIS 10.x Compatible version

\subsection{Methods of Data Processing}

\subsubsection{Study Area Boundary}

Map of study area acquires from Google in JPG format. And also open in Arc Map to geo reference and make the feature class of study area boundary. Select the polygon to digitize the boundary of our study area. Note that before digitizing also set the spatial reference system of feature class Boundary of study Area is in the form of shape file. To validate the result of digitizing shape file convert in to KML. KML file can export into Google earth.

\subsubsection{DEM}

Dem is downloaded from ASTER GDEM.

\subsubsection{Clipping}

Extract by Mask tool is used for clipping. DEM is clipped with boundary shapefile.

\subsubsection{TIN}

Digital Elevation Model (DEM) is converted into Triangular Irregular network. Drawing river.

Digitize river on TIN.

Drawing centerline.

Digitize river central line on TIN.

Drawing left and right banks.

Digitize both left and right banks.

Digitize flow path.

Digitize river' flow path.

Digitize flow path.

Digitize flow paths.

\subsubsection{Post Processing}

All preprocessing is now ready for input HEC RAS model. Different tools of HEC-Geo-RAS as well as HEC-RAS are applied. At this stage we will run the model. This SDF File (model file) will import in ARC MAP and using tools of HEC GeoRAS We generate water surface. 


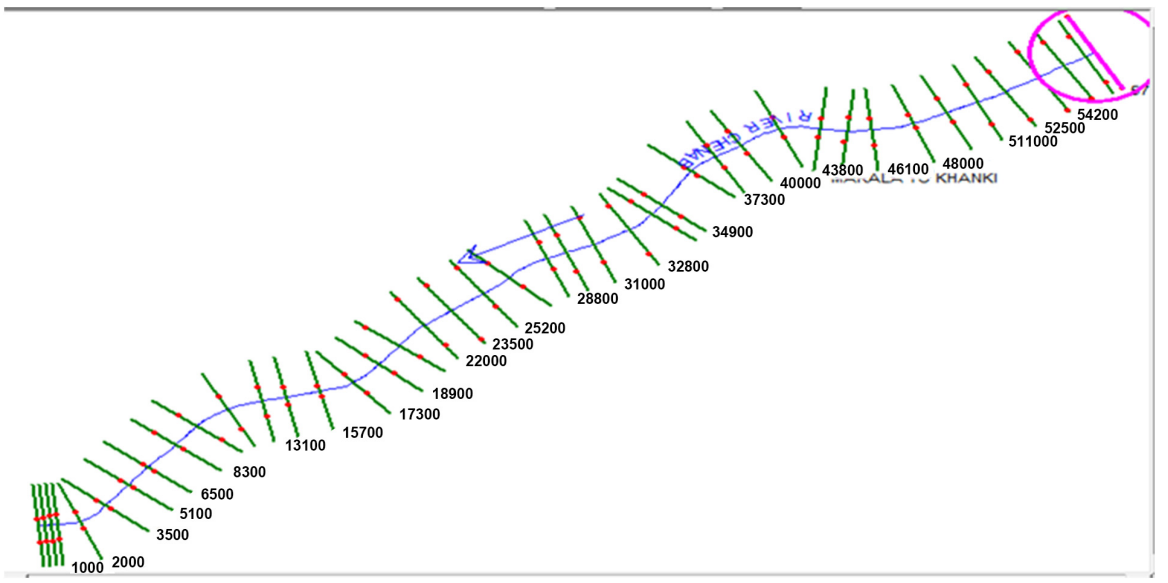

Figure 5. Cross section on river stream.

\subsubsection{Output}

Finally, we obtained hazards maps on the basis for different return periods, e.g. 3 years, 5 years, 10 years etc.

\subsubsection{ArcGIS Tools}

ArcGIS is a Geographical Information System (GIS) for working with maps and geographic information. It is used for creating and using maps, compiling geographic data, analyzing mapped information, sharing and discovering geographic information, using maps and geographic information in a range of applications, and managing geographic information in a database. The system provides an infrastructure for making maps and geographic information available throughout an organization, across a community, and openly on the Web. For this purpose, we add the data in ArcGIS as shown in Figure 6.1 and data layers are shown in Figure 6.2.

\subsection{Add Data}

\subsubsection{Extract by Mask (Spatial Analyst)}

Extract the cells of a raster that correspond to the areas defined by a mask. Input mask data defining areas to extract as shown in Figure 7.1 and Figure 7.2. This is a raster or feature dataset.

\subsubsection{Raster to TIN (3D Analyst)}

Convert a raster to a triangulated irregular network (TIN) dataset. Converting a raster to a TIN will not, in and of itself, produce a better surface. You need ancillary data that's compatible with, and improves, the surface definition. Such data could be added to the TIN using the Edit TIN tool. The default maximum allowable difference between the height of the input raster and the height of the output TIN is $1 / 10$ of the $\mathrm{z}$ range of the input raster (Figure 8).

\subsubsection{HEC Geo-RAS}

Using tool draw centerline, left and right bank lines and flow path Centerline as shown in following Figure 9. 


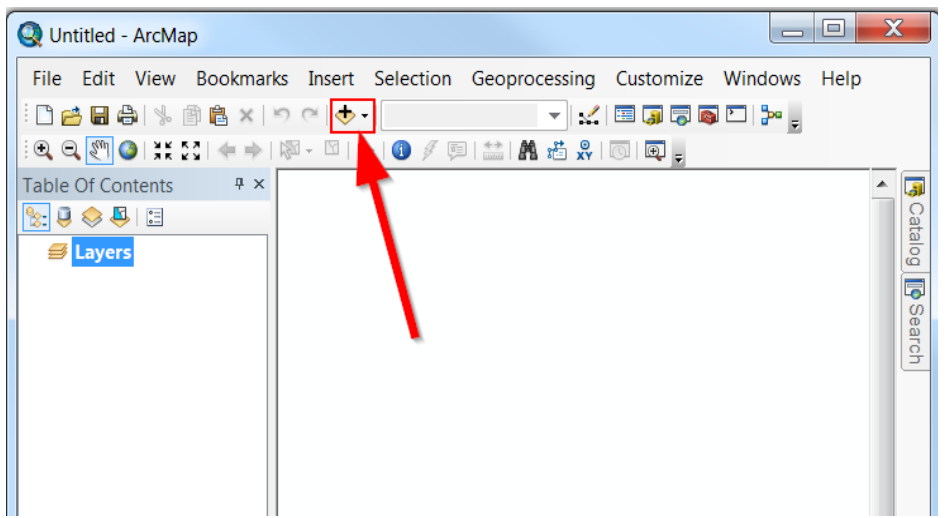

Figure 6.1. Add data by this tool.

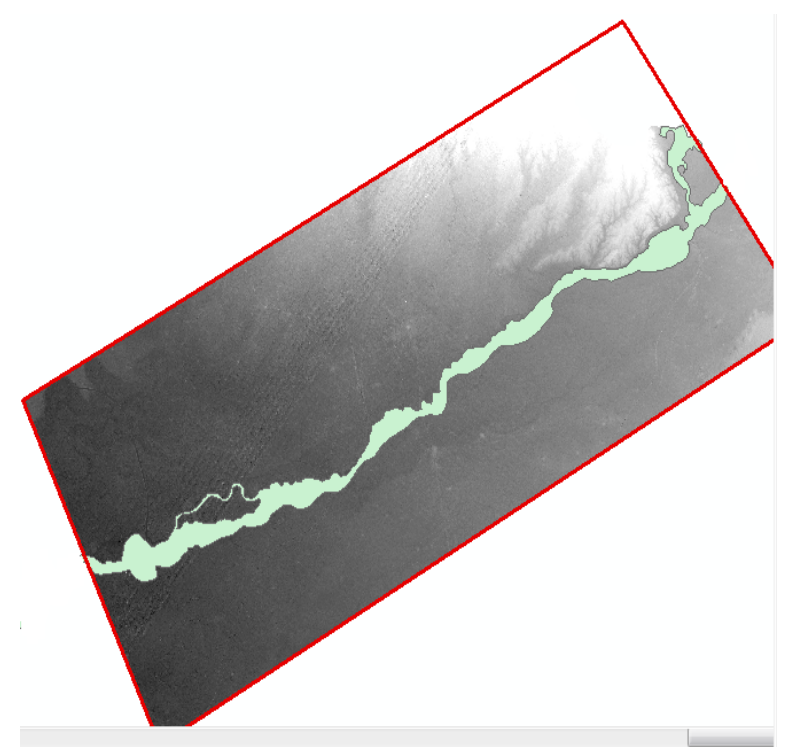

Figure 6.2. Chenab river, DEM, and boundary.

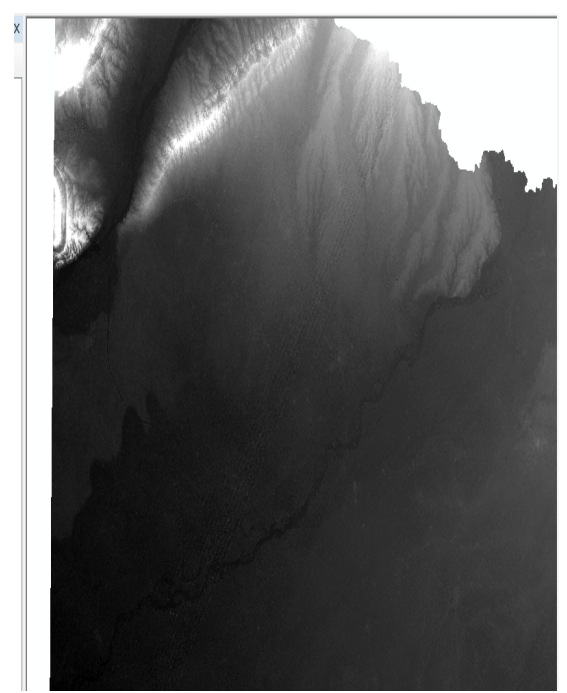

Figure 7.1. Image. 


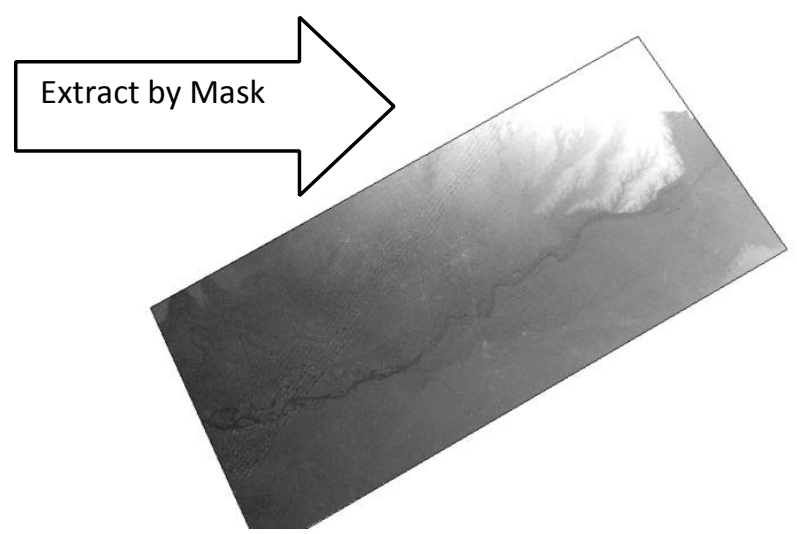

Figure 7.2. Extract by Mask.

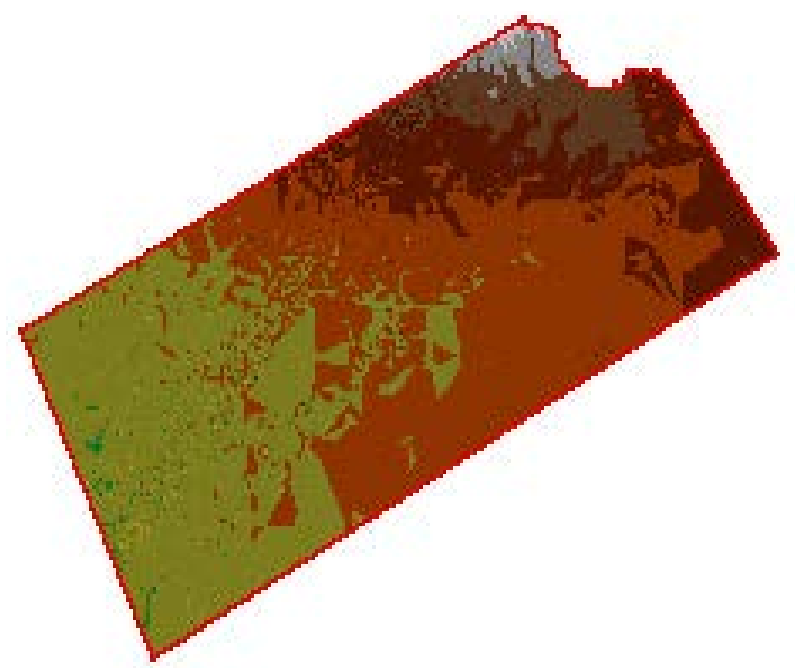

Figure 8. Convert DEM into TIN by using RASTER TO TIN (3D Analyst).

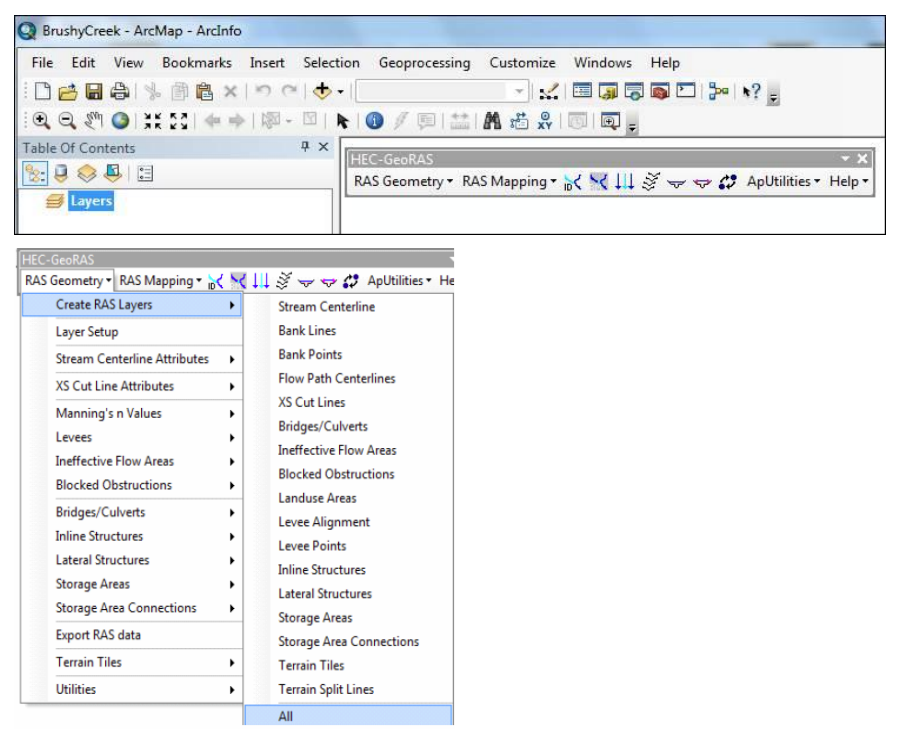

Figure 9. Tool selection. 
In following Figure 10, stream center line, bank line and flow direction is shown.

\subsubsection{Construct XS Cut Lines}

Tool bar is shown in Figure 11 from which XS Cut line is selected. Then cross section layer is exported in the form of RAS data as shown in Figure 12. This RAS DATA is imported in HEC RAS.

\subsubsection{HEC RAS Tools}

Hydrologic Engineering Center's River Analysis System allows the user to perform one-dimensional steady flow, one and two-dimensional unsteady flow calculations, sediment transport/mobile bed computations, and water temperature/water quality modeling. http://www.hec.usace.army.mil/software/hec-ras/

For adding Geometry data we click on $\measuredangle$. We import GIS DATA as shown in Figure 13. Results are shown in Figure 14 and Figure 15.

\subsubsection{Option Tool}

Assigning main channel MANNING'S $\mathrm{n}$ values or $\mathrm{k}$ values as shown in Figure 16.1 and Figure 16.2. The $k$ value or manning's $n$ value of Chenab river is 0.03 and $\mathrm{n} \# 2$ and $\mathrm{n} \# 3$ values are 0.035 .

\subsubsection{SAVE Geometry File}

Save Geometry Data as shown in Figure 17.

\subsubsection{Enter Study Flow Tool}

For adding Geometry data we click on $\underline{\underline{\underline{T}}}$. We can enter many numbers of profiles. Each Profile shows different return period .we enters peak flow data which we determine by DFW, as shown in Figure 18. Then we set Boundary Conditions.

Now we will set boundary Conditions as shown in Figure 19 and Figure 20. For this we click on normal depth button and enter the value of Upstream and Downstream Chenab values. These values almost equals to 0.002 . Click OK and save Study Flow.

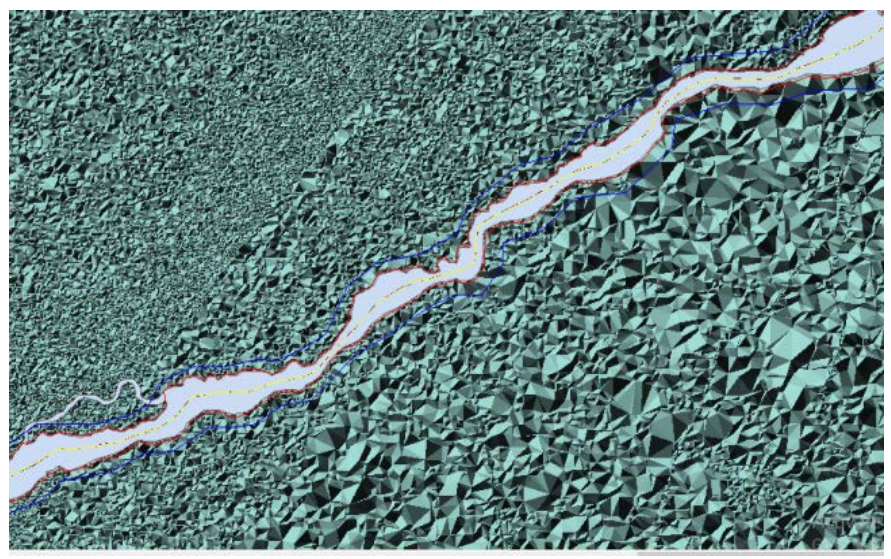

Figure 10. Stream Centre line, bank line and Flow paths. 


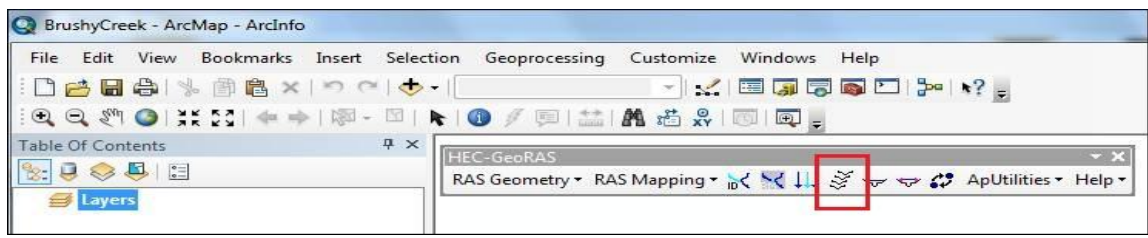

Figure 11. Tool bar.

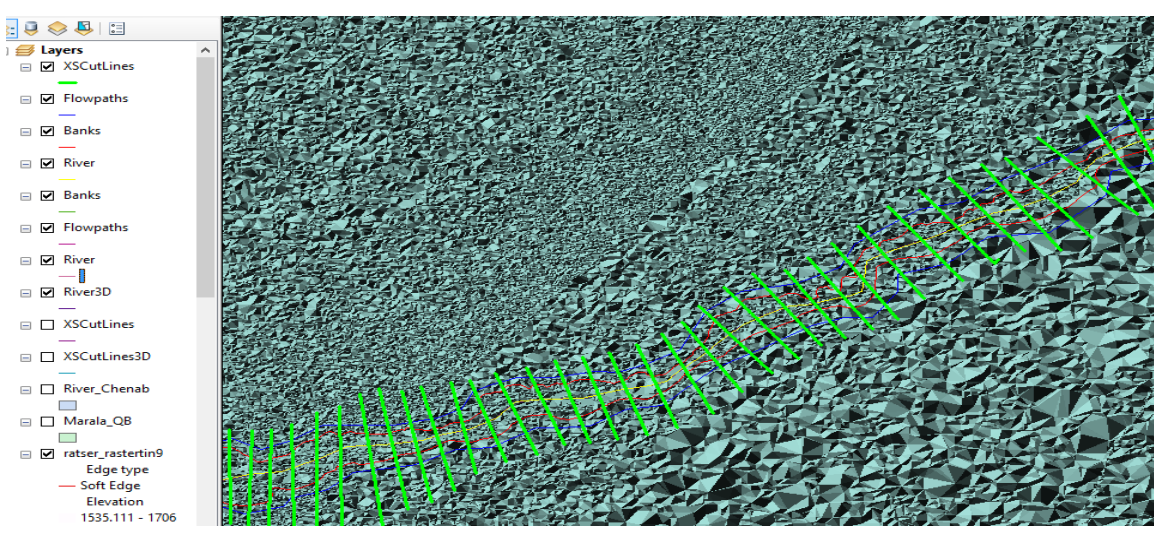

Figure 12. Cross Section layer exported as RAS DATA.

\section{HEC-RAS User Interface}

$\begin{array}{lll}\text { Unsteady Flow Data: } & \text { Unsteady Flow Analysis: } & \text { XYZ Perspective Plot: } \\ \text { Edit and/or enter } & \text { Perform an unsteady flow } & \text { View 3D multiple cross } \\ \text { unsteady flow data } & \text { simulation } & \text { section plot }\end{array}$

unsteady flow data simulation

section plot

\section{\begin{tabular}{l|l} 
Geometric Data: & Cross Sections: \\
Edit and/or enter & View cross
\end{tabular} geometric Data View cross}

Hydraulic Properties:

Plots and tables of hydraulic properties

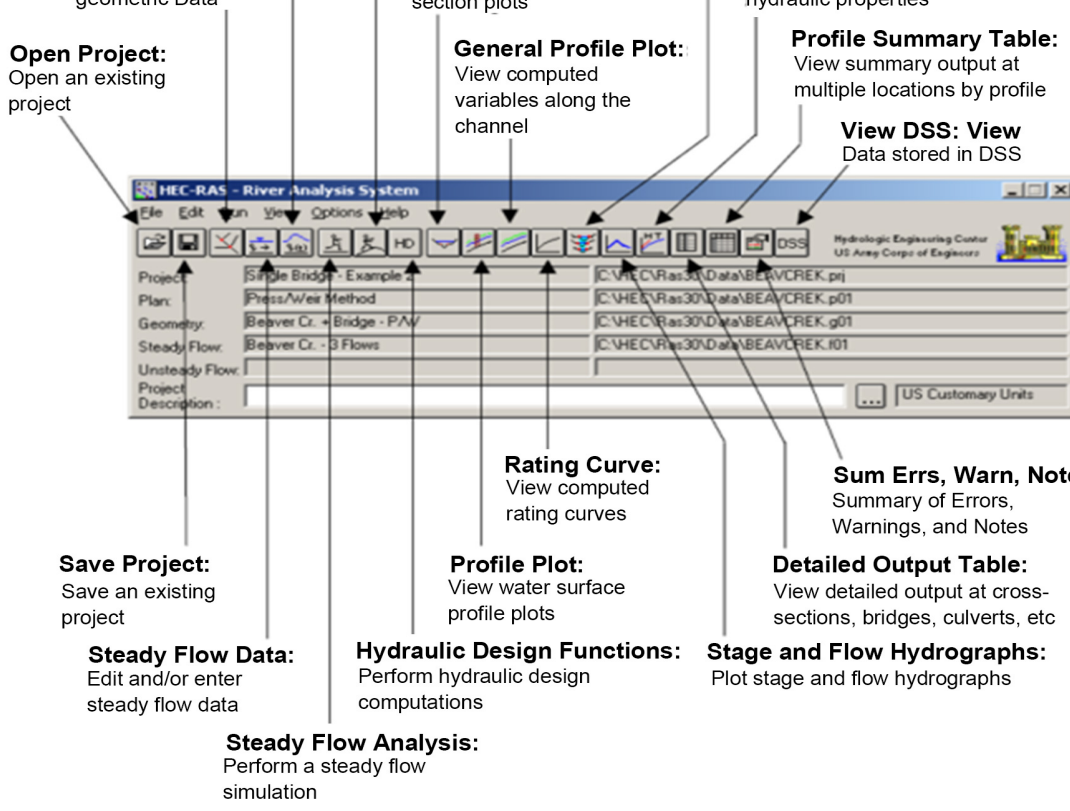

Steady Flow Data: Edit and/or enter steady flow data

Profile Plot:
View water surface
profile plots

Hydraulic Design Functions: computations

Steady Flow Analysis:

Perform a steady flow

simulation

Figure 13. Enter geometric data tool. 


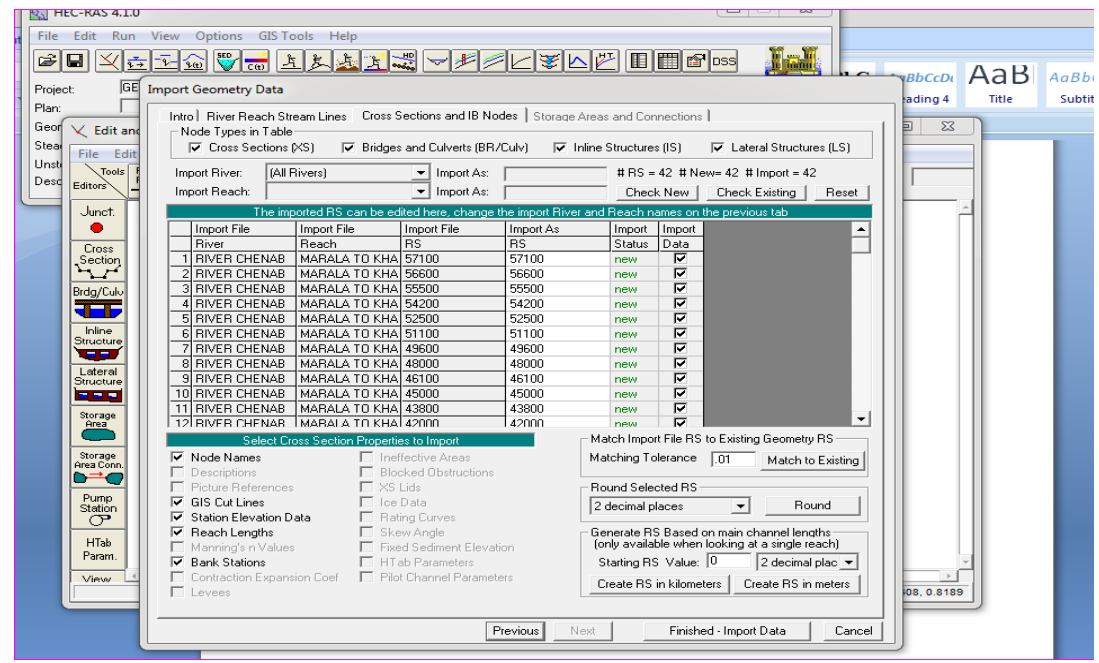

Figure 14. Results.

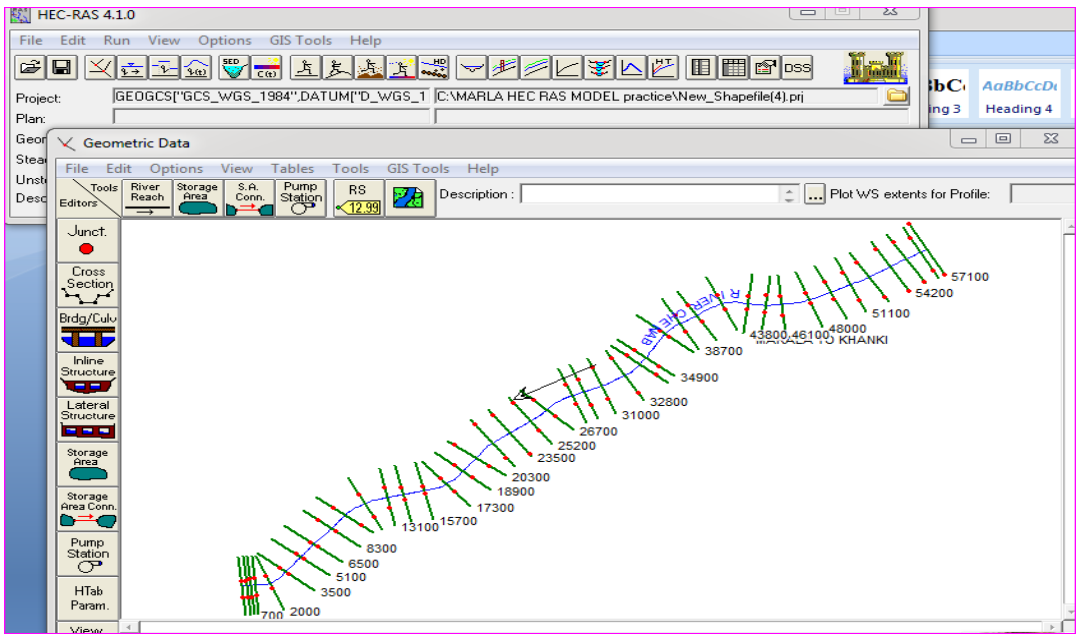

Figure 15. Results.

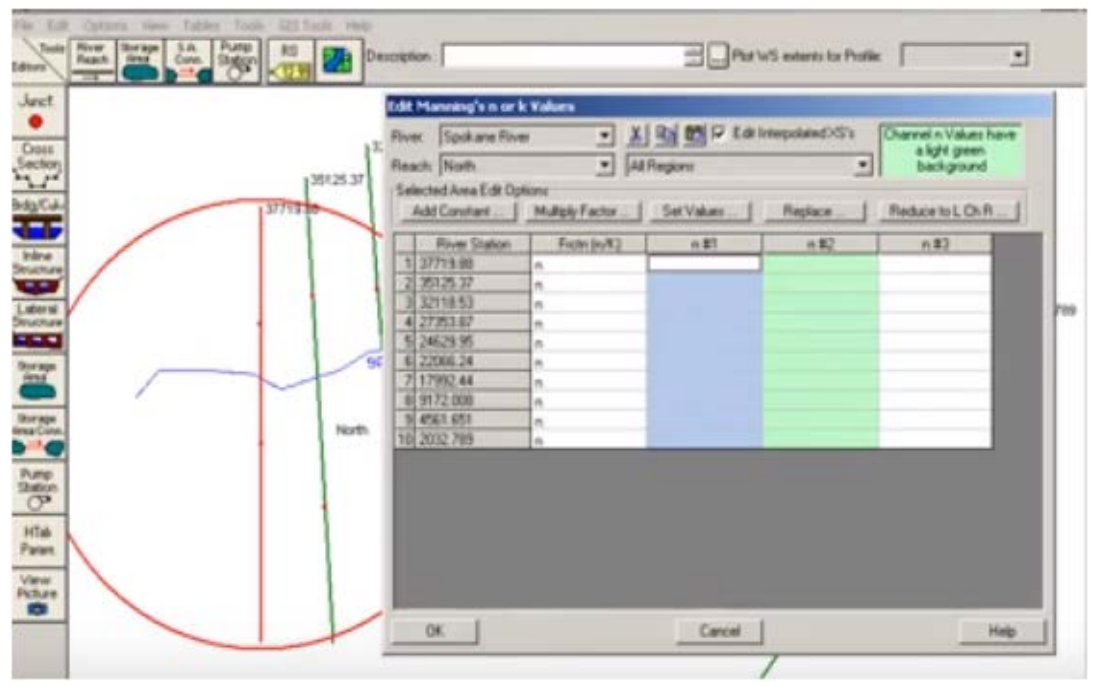

Figure 16.1. K value assigning window. 


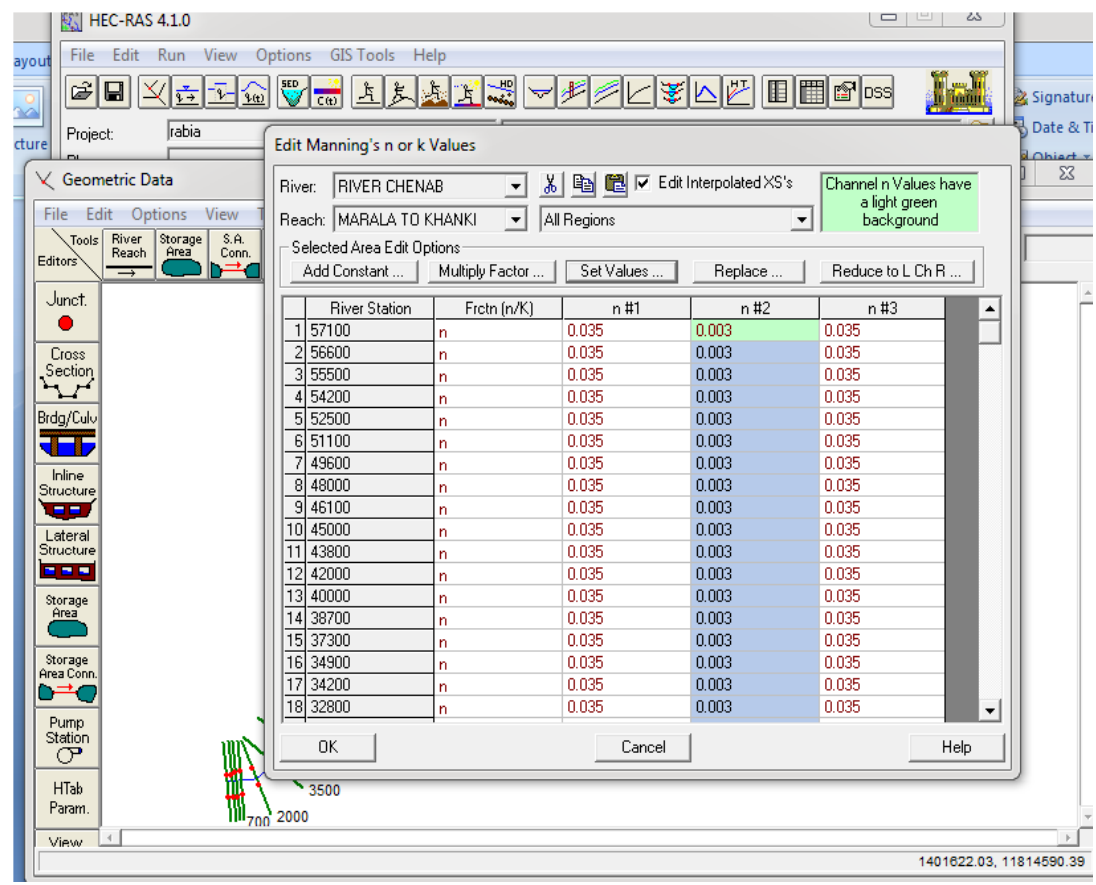

Figure 16.2. K value assigning window.

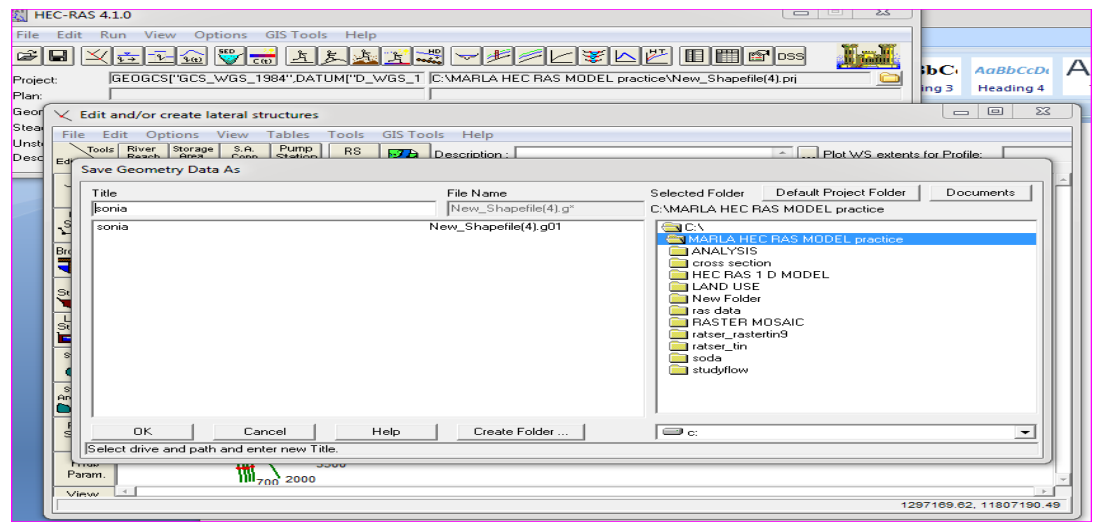

Figure 17. Save data window.

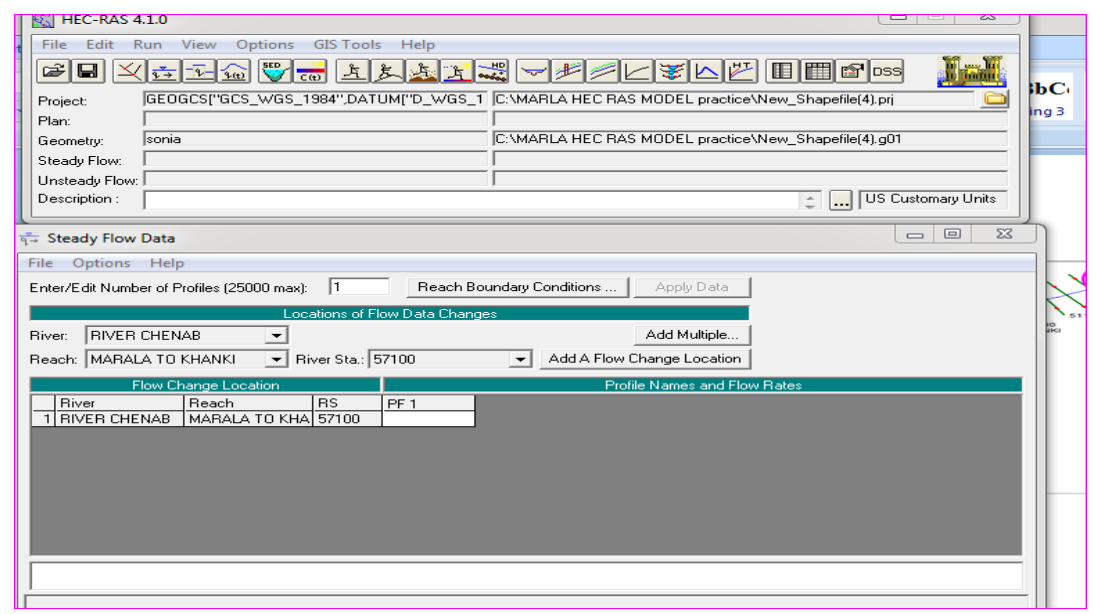

Figure 18. Study flow tool window. 


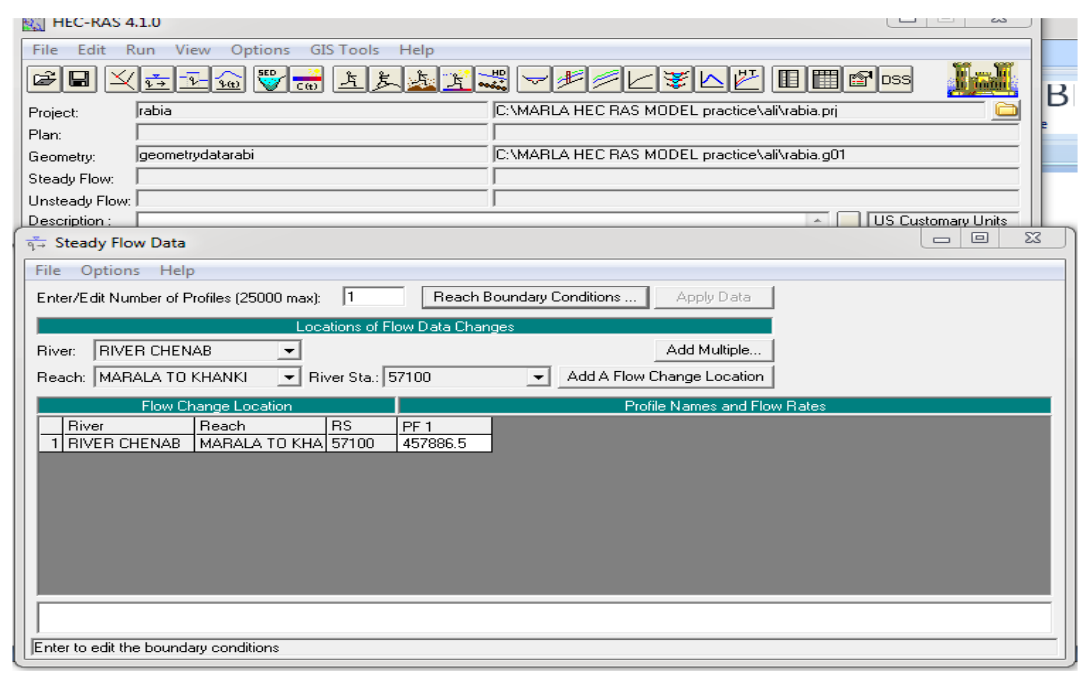

Figure 19. Up Stream and down stream value setting window.

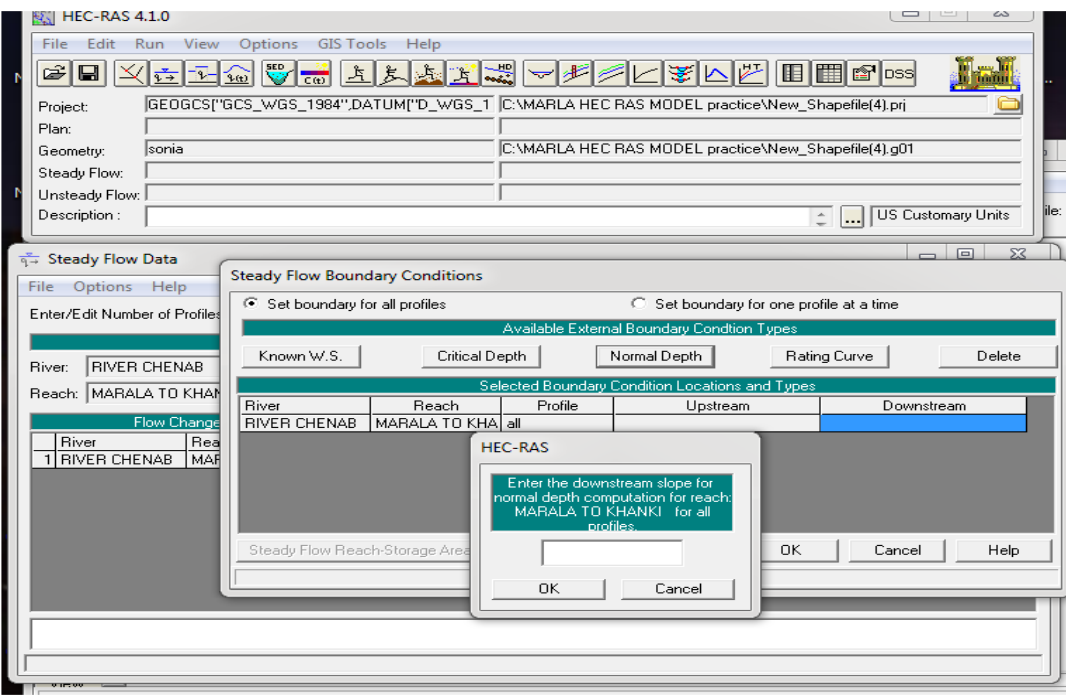

Figure 20. Up stream and down stream value setting window.

\subsubsection{Run Model}

We will run model by clicking on $\frac{\text { RAS 4.1.0 }}{\text { fit }}$ Run $v_{i}$ (RUN) and then compute after type our plan. As shown in Figure 21, the running result is shown in Figure 22.

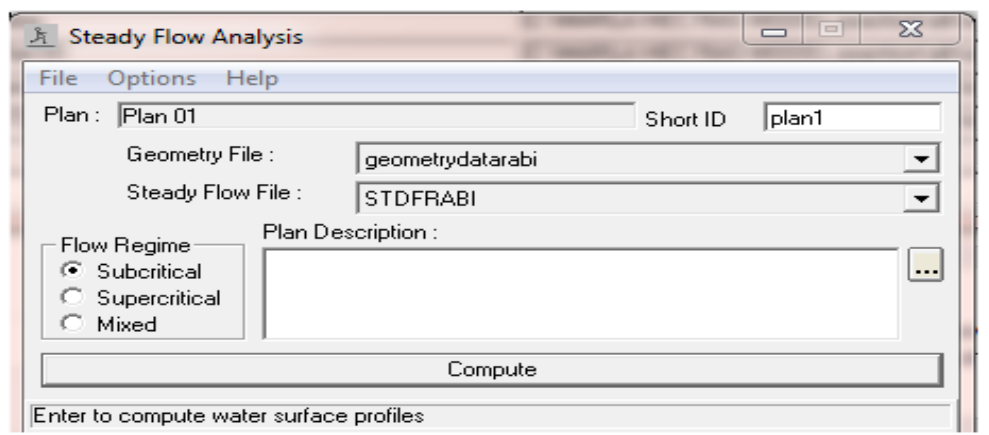

Figure 21. RAS run window. 


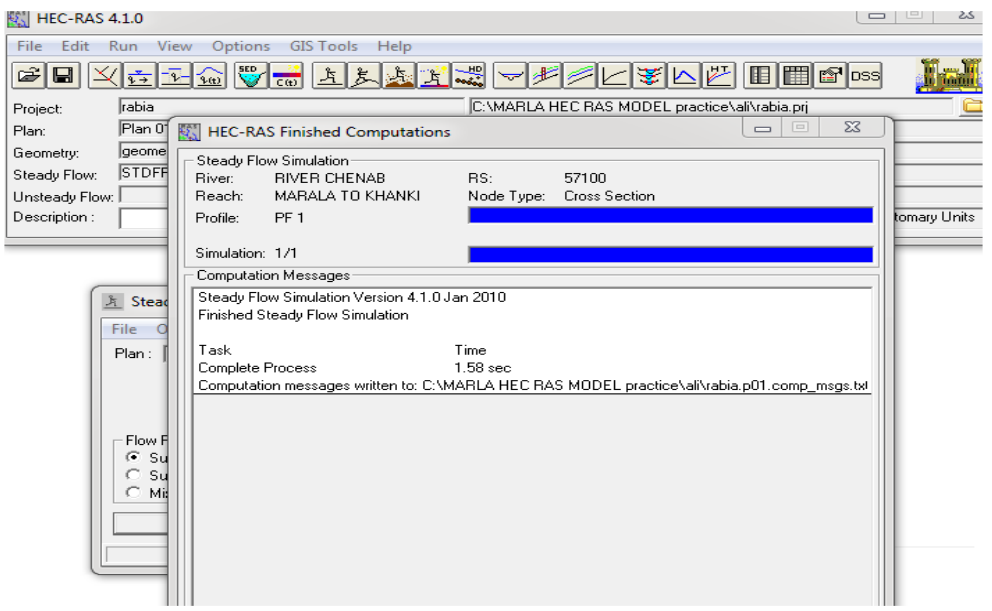

Figure 22. Result.

\subsubsection{Cross Section Tool}

The following tool is used to view cross sections plot results after computing the model $\rightarrow$ as shown in Figure 23.

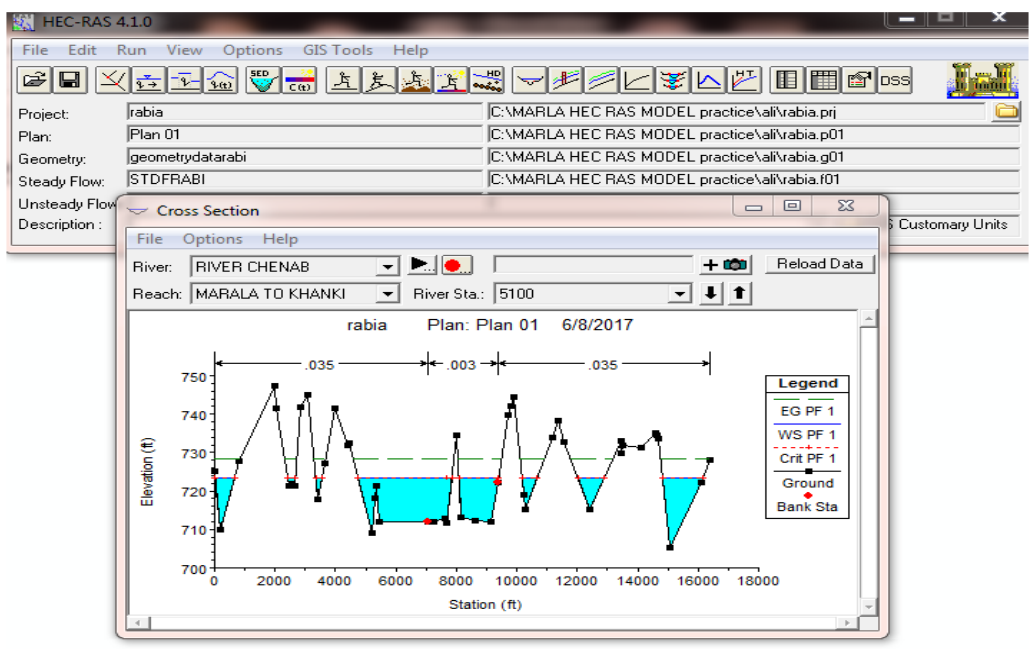

Figure 23. Crosse section tool.

\subsubsection{Rating Curve Tool}

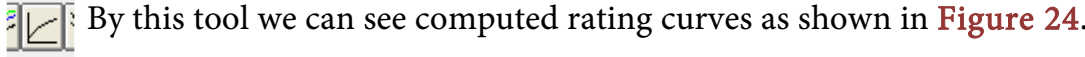

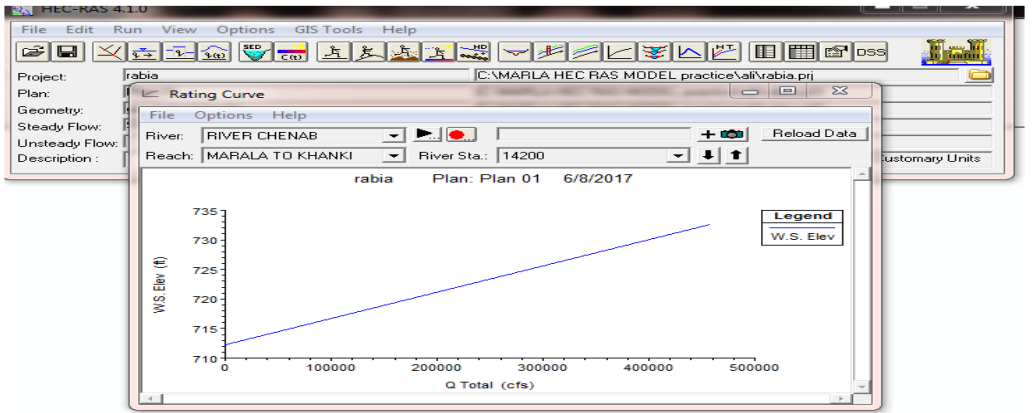

Figure 24. Rating center window. 


\subsubsection{Profile Plot Tool}

This tool is used to view the water surface profile plot as shown in Figure 25.

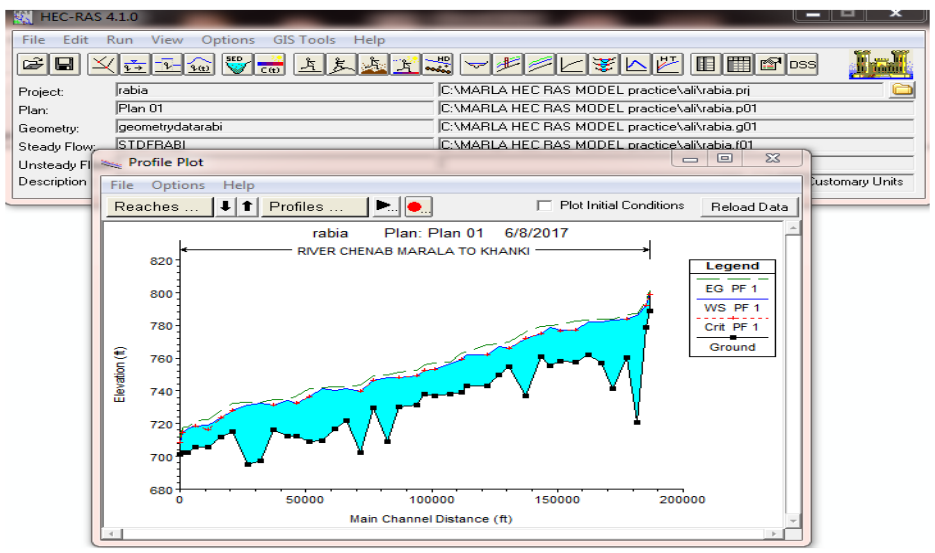

Figure 25. Profile plot.

\subsubsection{Detailed Output Table Tool (Figure 26)}

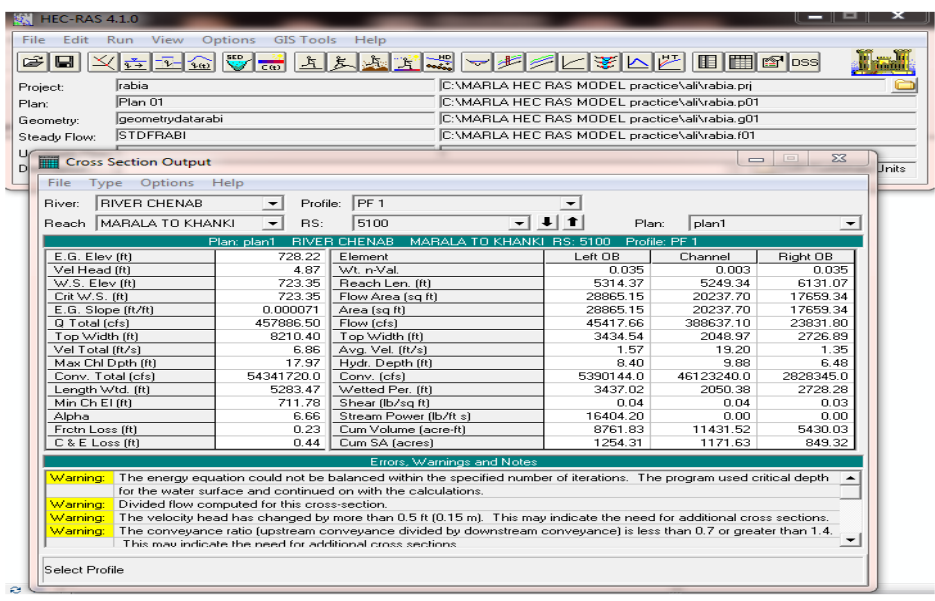

Figure 26. Cross sections bridges.

\subsubsection{Profile Summary Table Tool (Figure 27)}

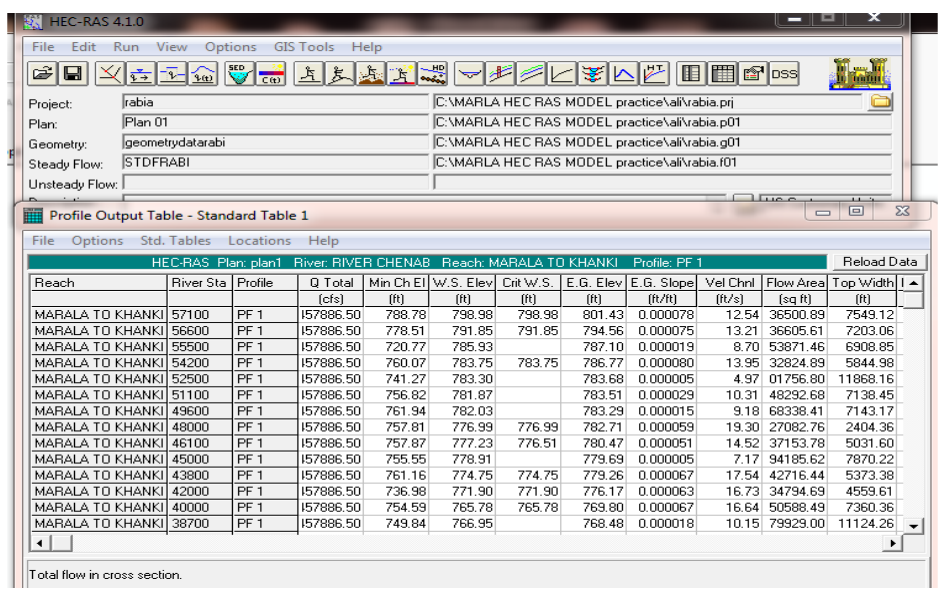

Figure 27. Output summary at multiple locations profile. 


\subsubsection{Export GIS Data (Figure 28)}

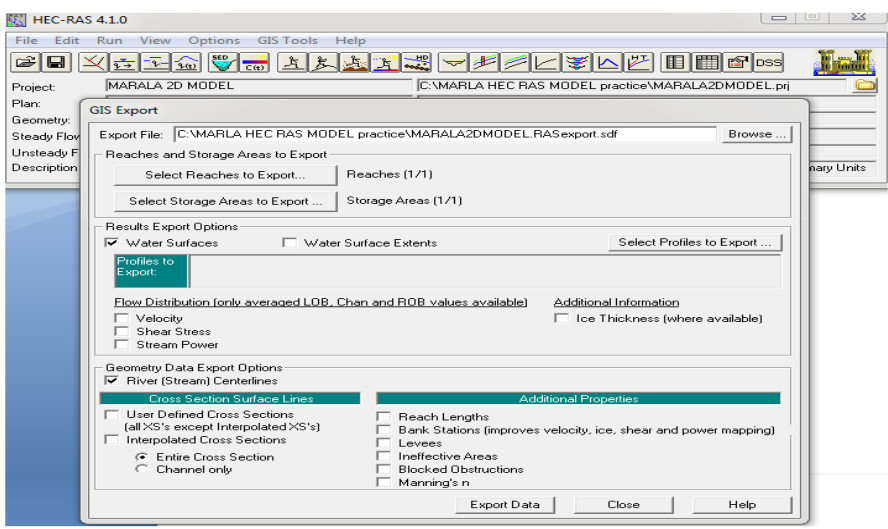

Figure 28. Export GIS Data.

\subsubsection{HEC Geo-RAS Tools (ArcGIS Extension) (Figure 29; Figure 30)}

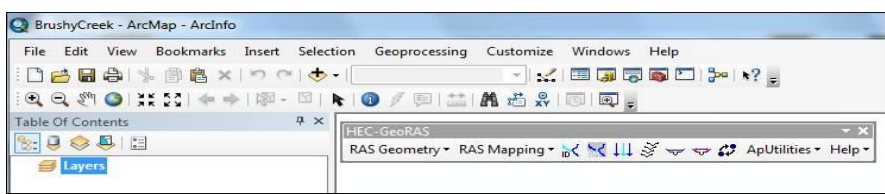

Figure 29. Conversion to SDF to XML.

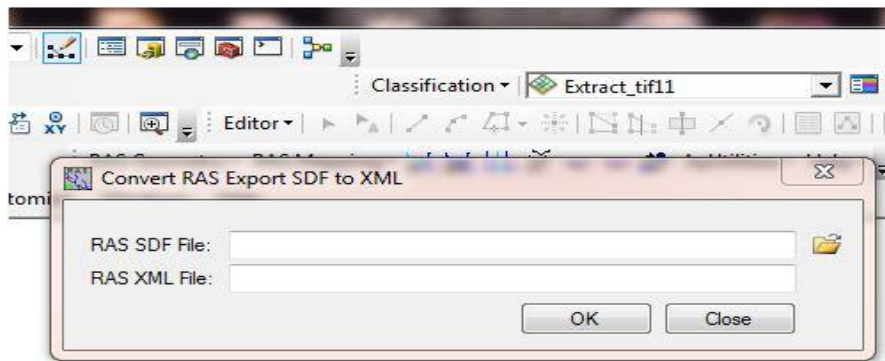

Figure 30. Conversion SDF file to XML file.

\subsubsection{RAS Mapping Tool (Figure 31)}

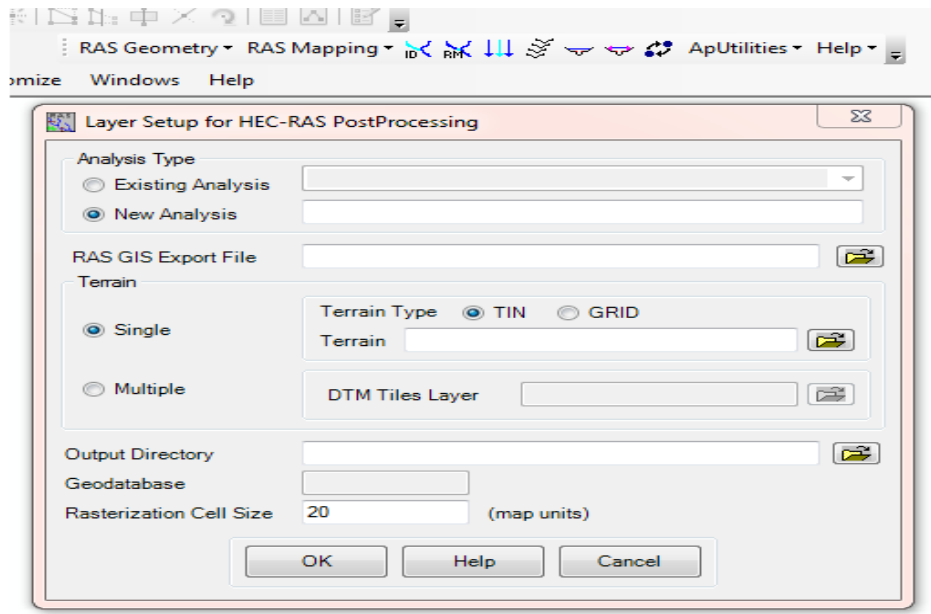

Figure 31. Layer setup window. 
RAS MAPPING TOOL then LAYER SETUP TOOL. It will be done when you saved your .mxd file.

\subsubsection{RAS Data Import Tool (Figure 32)}

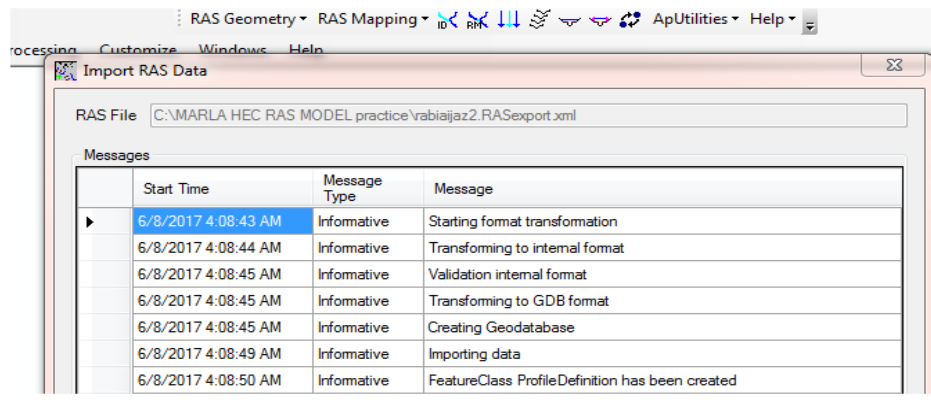

Figure 32. Import RAS DATA.

\subsubsection{Flood Delineation Tool}

Flood delineation using grid tool is used to flood plain mapping as shown in Figure 33.

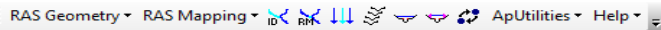

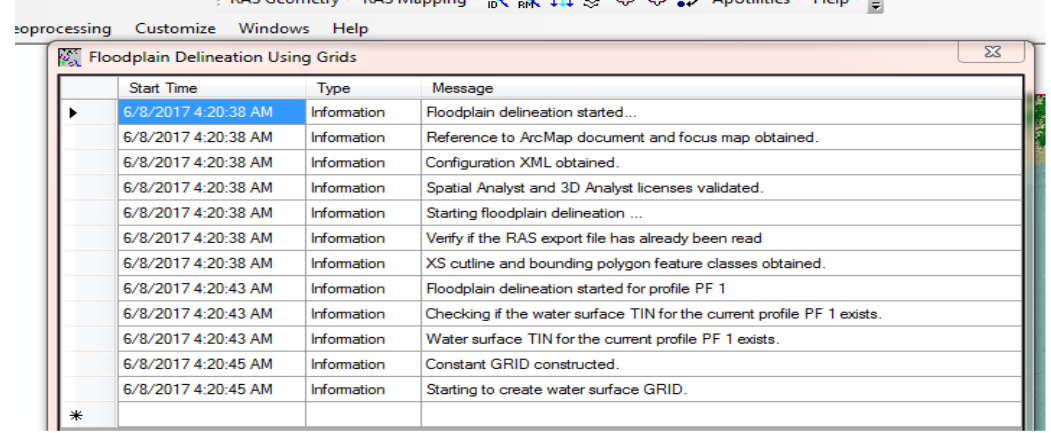

Figure 33. Flood delineation using grid tool is used to flood plain mapping.

\subsubsection{Flood Plain}

A floodplain or flood plain is an area of land adjacent to a stream or river that stretches from the banks of its channel to the base of the enclosing valley walls and experiences flooding during periods of high discharge as shown in Figure 34.

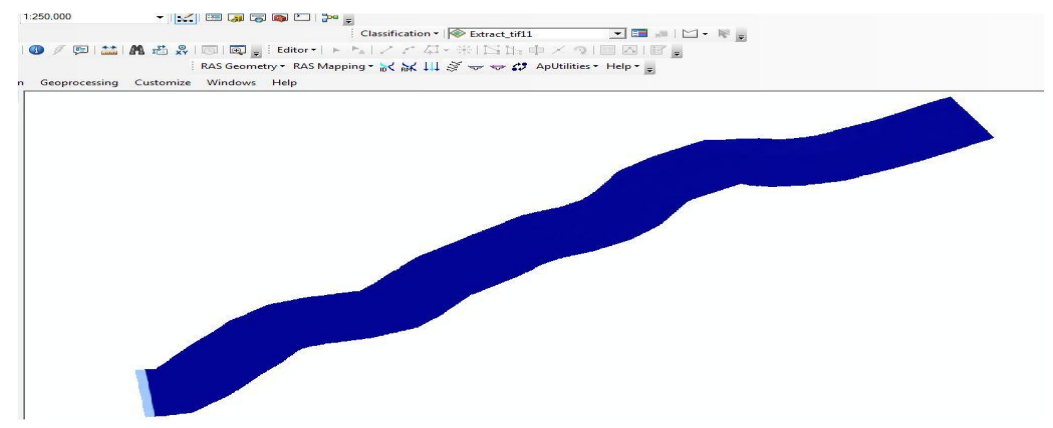

Figure 34. Floodplain for 10 years. 


\subsubsection{Layer to KML}

This tool converts a feature or raster layer into a KML file containing a translation of Esri geometries and symbology. This file is compressed using ZIP compression, has a .kmz extension, and can be read by any KML client including ArcGIS Explorer, ArcGlobe, and Google Earth.

\section{Results}

After evaluation obtained following results after flood frequency analysis by DFW.

\begin{tabular}{ccccc}
\multicolumn{2}{l}{$\begin{array}{l}\text { Gumbel Extreme Value Type-I Distribution, [ML method] } \\
\text { Recurrence }\end{array}$} & Peak & $95 \%$ Confidence & \multicolumn{2}{l}{ Standard } \\
Interval & Discharge & Limits & Error \\
(Years) & (cfs) & (cfs) & (cfs) \\
2 & 278395.0 & $\{253172.4-$ & $303617.7\}$ & 12868.69 \\
5 & 470840.1 & $432130.3-$ & $509549.9\}$ & 19749.88 \\
10 & 598255.5 & $\{548597.6-$ & $647913.4\}$ & 25335.66 \\
15 & 670142.2 & $\{614007.1-$ & $726277.3\}$ & 28640.36 \\
100 & 997226.0 & $\{910399.8-$ & $1084052.3\}$ & 44299.09
\end{tabular}

Results show 2, 5, 10, 15,100 years return period peak discharge value, these values indicates if flood accuracy in future that return period so peak flow discharge would be.

\subsection{HEC RAS Model Results}

After preprocessing in HEC Geo RAS model run in HEC RAS for steady flow analysis Geometric data and steady flow data are used to analyze the Subcritical Flow Regime. Flow regime: the condition of flow for the river. In our case this is Subcritical. This means that there are subcritical conditions at the downstream end, and that you can calculate the water surface upstream and downstream.

Similarly, we can find out different flood extent on the basis of different return time period e.g. 2, 5, 10, 15 and 100 using peak value of water flow as shown in Figures 35-39 and Figure 40 respectively. Figure 36 shows that return the flood during the period of 5 years.

\subsection{Inundation Mapping}

Floods: The map library is a set of maps that show where a series of water levels in a local river or river flood.

The risk of flood is regarded as being the product of the probability of occurrence of risings and the consequences caused by these events [27]. By having a diagram total of the situation, it would be not only possible to manage the risk, to take the necessary measurements in order to eliminate the life losses and to 


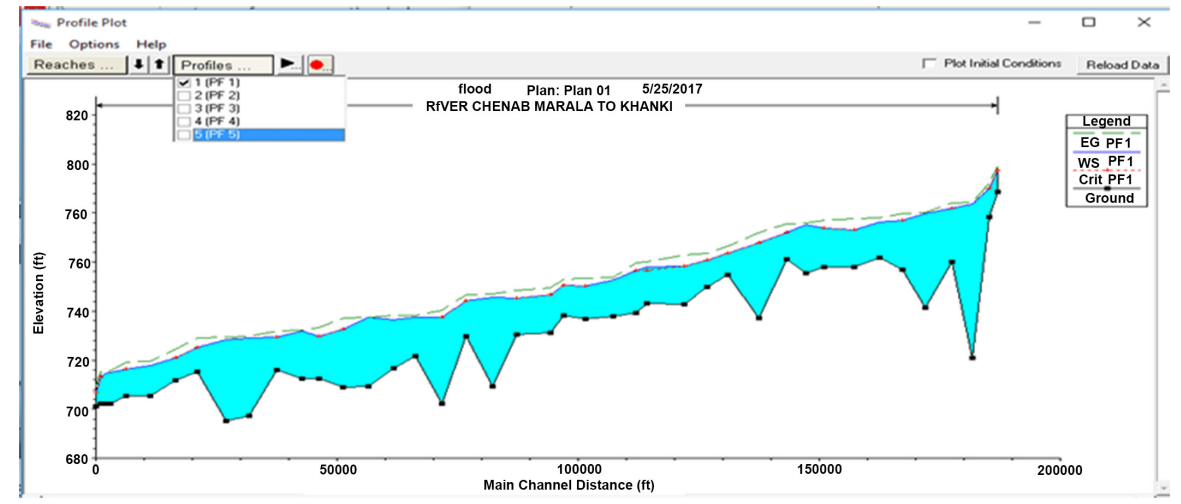

Figure 35. Profile plot of two years' return flood.

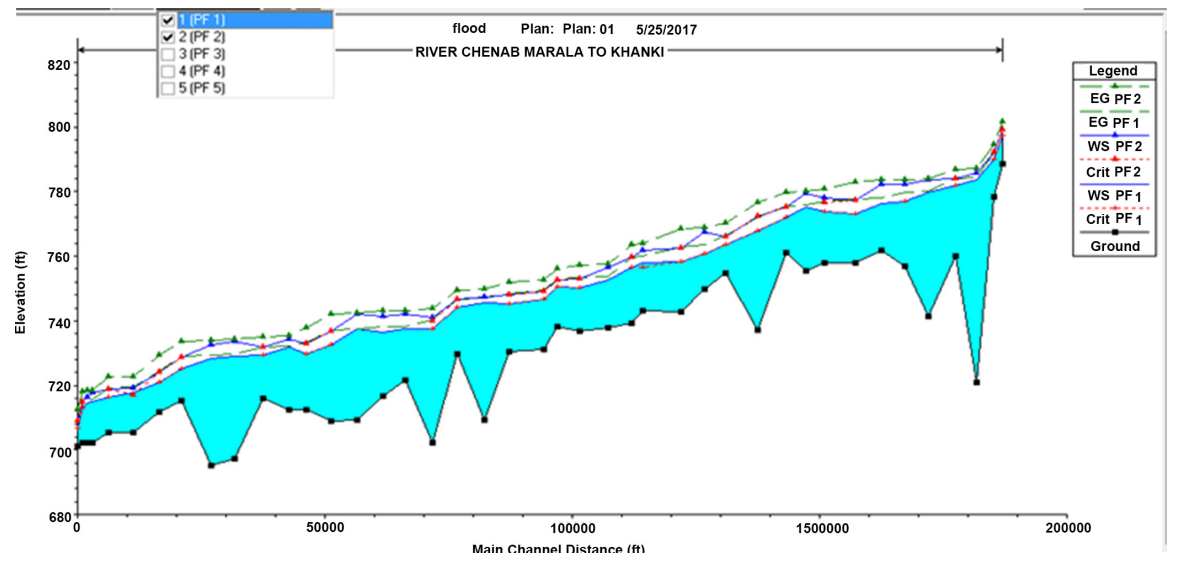

Figure 36. Profile plot of five years' return flood.

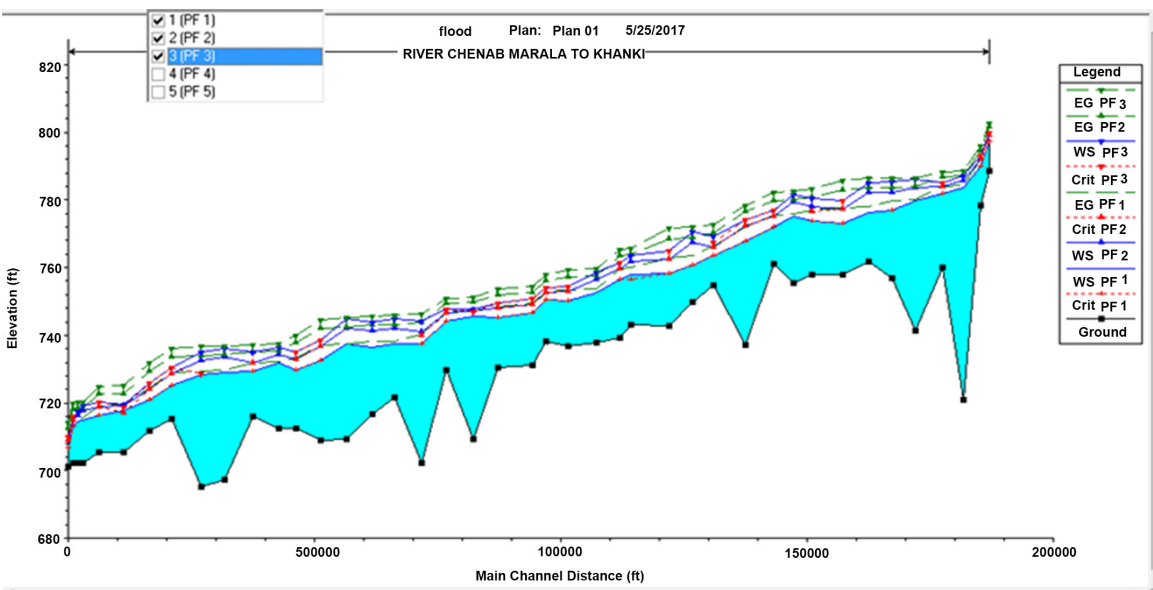

Figure 37. Profile plot of ten years' return flood.

limit the material losses, but also to have diversified possibilities to envisage an adapted dimensioning of the works water-supply engineering [28].

At present, GIS modelling for floods or delimiting some flood prone areas is very advanced, and numerous mathematical methods for calculating the extent of a river (according to its flow rate, the water infiltration rate into the soil, land use etc.) have been developed as shown in Figure 41. These mathematical 


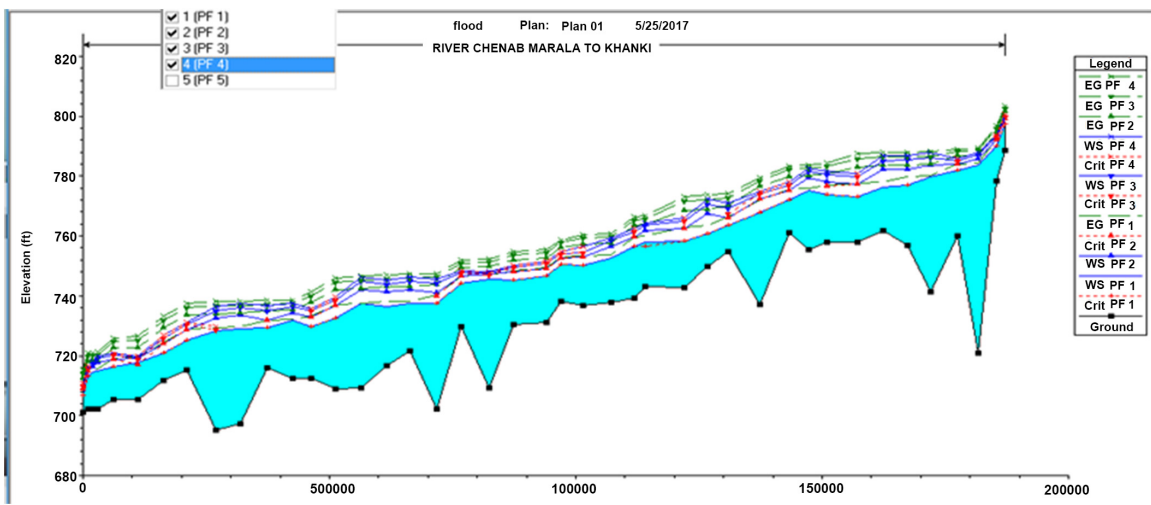

Figure 38. Profile plot of fifteen years' return flood.

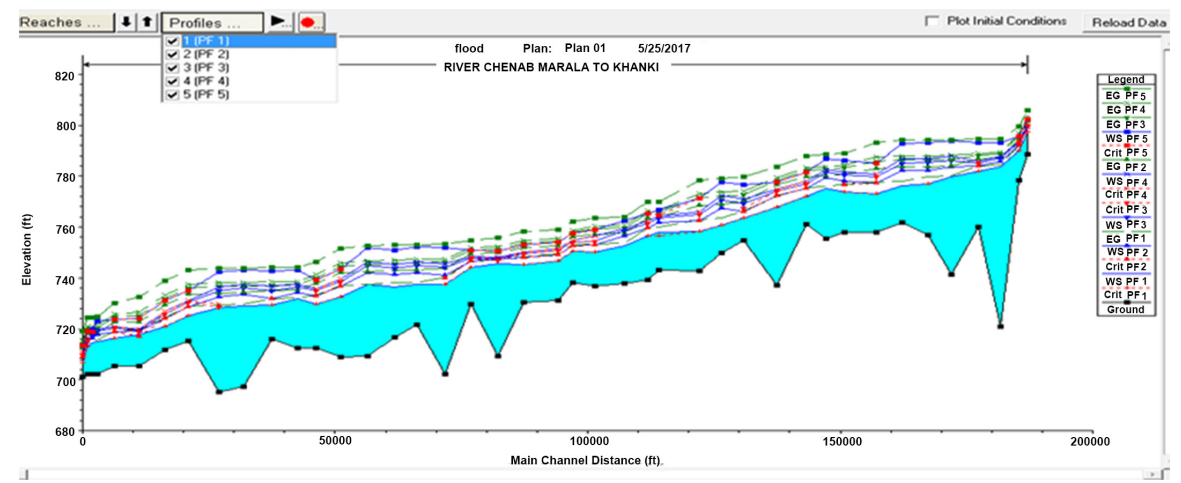

Figure 39. Profile plot of hundred years' return flood.

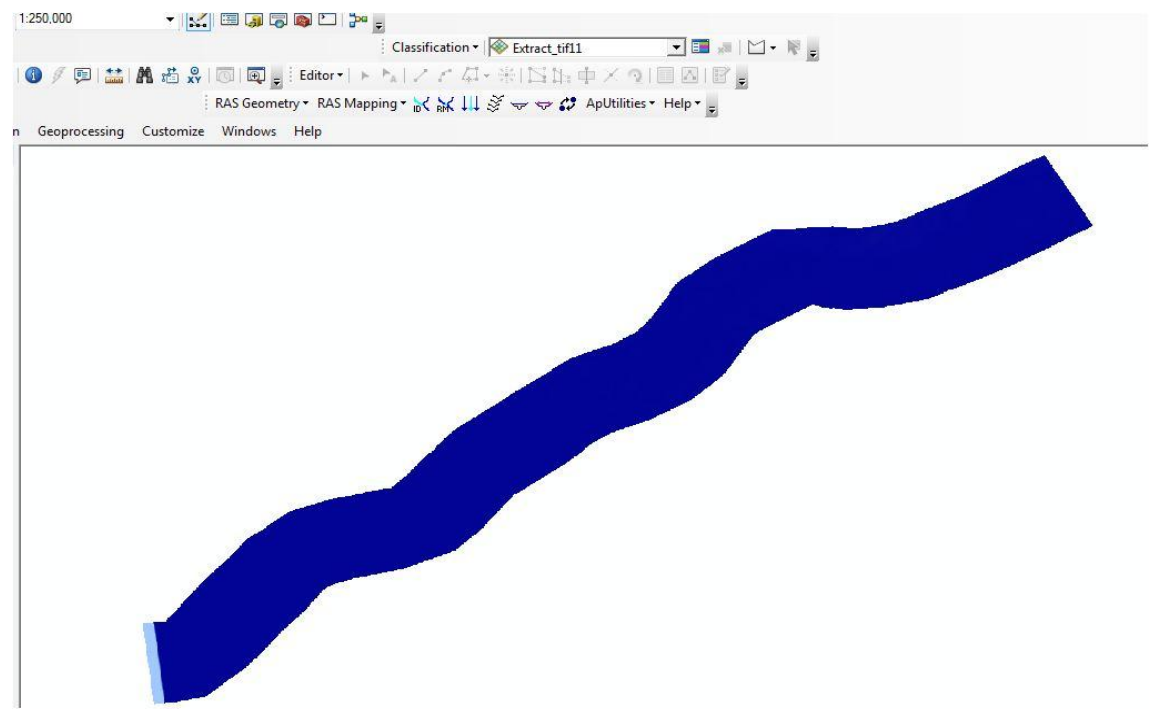

Figure 40. Floodplain for 15 years.

models have been integrated into GIS software, whose purpose is to create a model that would replicate the shape of the landscape as precise, as possible. The flood risk maps have a clear purpose of identifying vulnerable areas and the population that is exposed in a certain region; they represent a useful tool during General Urban Plan creation, and intend to be used in the interdiction of 


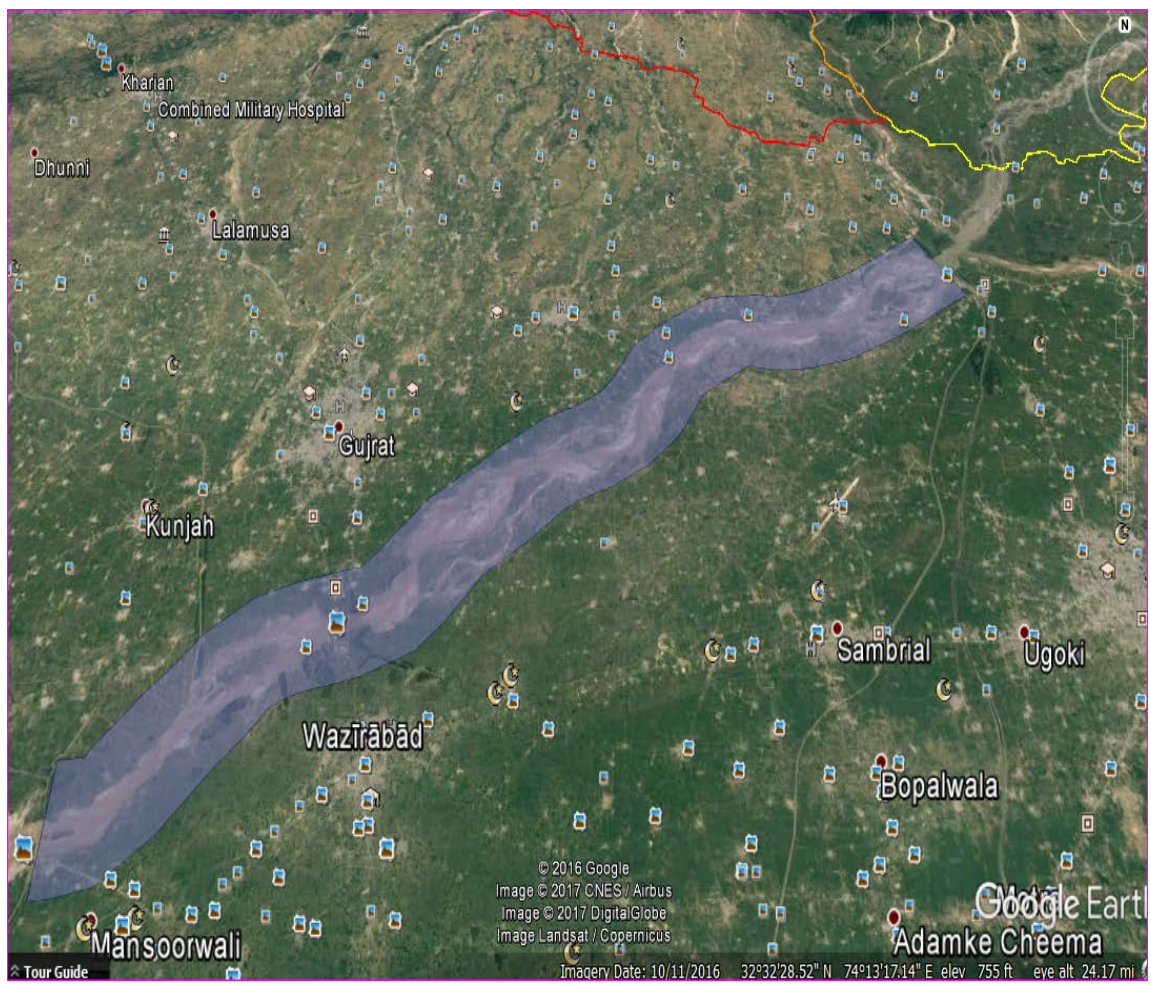

Figure 41. Year return period flood along Chenab.

constructing houses in the affected areas and creating management plans for emergency situations, as close as possible to the probabilities of certain events of this type [29].

Flood hazard maps for different return periods 10, 20, 50 and 100 years were conducted by Flood frequency analysis. Flood frequency analysis was used to predict design floods for sites along a river. We used annual peak flow of 35 years from 1980 to 2016. The technique used observed annual peak flow discharge data to calculate statistical information such as mean values, standard deviations, skewness, and recurrence intervals. Flood frequency curve were obtained which is a graph showing the relationship between flood magnitude and their recurrence interval for a specified site. Different formulas, i.e. Gumble Formula Figure 3.10, Hazen Formula, Figure 3.8, Blom Formula Figure 3.6, Relative frequency formula Figure 3.9, Wiebell formula 3.11 and Gingorton formula were applied. The best fitted formula for our data was Gumble Formula Figure 3.10. In the phase of Preprocessing we made HEC-RAS model and then this model imported to Arc GIS for post processing. This model results showed that different area is predicted under water in different return periods. Figure 6 shows affected areas after five years' return period.

Flood hazard and flood risk of losses mitigated by multiple risk characteristics combined into a meaningful spatial planning map [30] [31]. The forecast and the control of the damage caused by this type of disasters, particularly require the identification of the vulnerable areas and the determination of the factors 
and the damages generated by these catastrophes [32][33]. Remote sensing and GIS application in Sindh Province for flood risk management provide an approach to access hazard of flood [34]. The results of the simulations carried out by HEC-RAS represent the result of a combination of several models brought into consideration. These results made it possible to inform about fluctuations in the appearance of the hydro-gram of rising.

\section{Conclusion}

The foremost spotlight of this study was on assessing the appropriateness of HEC-RAS model in simulating water surface profiles of river Chenab which was the main reason for river flooding in Punjab. The resultant outputs obtained from the use of one dimensional steady flow analysis using the HEC RAS model suggested assessing flood hazards maps for different return periods 10, 20, 50 and 100 years was conducted using annual peaks flow of 35 years from 1980 to 2016. The maximum discharges at up and down stream for different periods were obtained using Gumbel distribution model results which showed that different areas were predicted under water in different return periods and affected areas after five years' return period. However, further studies should be carried with HEC-RAS models that can be effectively utilized to improve and simplify the forecasts of areas likely to be inundated under a given flood. This method can only be best fit for limited areas of rivers.

\section{Conflicts of Interest}

The authors declare no conflicts of interest regarding the publication of this paper.

\section{References}

[1] Latif, M., Syed, F.S. and Hannachi, A. (2017) Rainfall Trends in the South Asian Summer Monsoon and Its Related Large-Scale Dynamics with Focus over Pakistan. Climate Dynamics, 48, 3565-3581. https://doi.org/10.1007/s00382-016-3284-3

[2] Adnan, S., Ullah, K., Gao, S., Khosa, A.H. and Wang, Z. (2017) Shifting of Agro-Climatic Zones, Their Drought Vulnerability, and Precipitation and Temperature Trends in Pakistan. International Journal of Climatology. https://doi.org/10.1002/joc.5019

[3] Death, R.G., Fuller, I.C. and Macklin, M.G. (2015) Resetting the River Template: The Potential for Climate-Related Extreme Floods to Transform River Geomorphology and Ecology. Freshwater Biology, 60, 2477-2496. https://doi.org/10.1111/fwb.12639

[4] Atallah, M.H., Hazzab, A., Seddini, A., Ghenaim, A. and Korichi, K. (2016) Hydraulic Flood Routing in an Ephemeral Channel: Wadi Mekerra, Algeria. Modeling Earth Systems and Environment, 2, 1-12. https://doi.org/10.1007/s40808-016-0237-0

[5] Yamani, K., Hazzab, A., Sekkoum, M. and Slimane, T. (2016) Mapping of Vulnerability of Flooded Area in Arid Region. Case Study: Area of Ghardaïa-Algeria. Modeling Earth Systems and Environment, 2, 147. 
https://doi.org/10.1007/s40808-016-0183-X

[6] Mirza, M.M.Q. (2003) Climate Change and Extreme Weather Events: Can Developing Countries Adapt? Climate Policy, 3, 233-248.

https://doi.org/10.3763/cpol.2003.0330

[7] Wu, W., Mhaimeed, A.S., Al-Shafie, W.M., Ziadat, F., Dhehibi, B., Nangia, V. and De Pauw, E. (2014) Mapping Soil Salinity Changes Using Remote Sensing in Central Iraq. Geoderma Regional, 2, 21-31. https://doi.org/10.1016/j.geodrs.2014.09.002

[8] Tariq, M.A.U.R. (2013) Risk-Based Flood Zoning Employing Expected Annual Damages: The Chenab River Case Study. Stochastic Environmental Research and Risk Assessment, 27, 1957-1966. https://doi.org/10.1007/s00477-013-0730-1

[9] Gaillard, C., Zagolski, F. and Bonn, F. (1997) Modelling of Human Dimension on Soil Erosion Processes for Remote Sensing Applications. IGARSS97. 1997 IEEE International Geoscience and Remote Sensing Symposium Proceedings. Remote Sensing-A Scientific Vision for Sustainable Development, 1, 122-124.

[10] Syvitski, J.P., Kettner, A.J., Overeem, I., Giosan, L., Brakenridge, G.R., Hannon, M. and Bilham, R. (2013) Anthropocene Metamorphosis of the Indus Delta and Lower Floodplain. Anthropocene, 3, 24-35. https://doi.org/10.1016/j.ancene.2014.02.003

[11] Qureshi, A.S. (2011) Water Management in the Indus Basin in Pakistan: Challenges and Opportunities. Mountain Research and Development, 31, 252-260.

https://doi.org/10.1659/MRD-JOURNAL-D-11-00019.1

[12] Shahid, M.A., Boccardo, P., Usman, M., Albanese, A. and Qamar, M.U. (2017) Predicting Peak Flows in Real Time through Event Based Hydrologic Modeling for a Trans-Boundary River Catchment. Water Resources Management, 31, 793-810. https://doi.org/10.1007/s11269-016-1435-2

[13] Zhao, W.L., Li, F.M., Mou, Y.L., Jia, C.J. and Sun, G.J. (2010) Simulation of Farming Suitability for Arid-Agriculture Using a GIS-Evaluation Approach in the Loess Plateau, China. 2010 World Automation Congress, Kobe, 19-23 September 2010, 107-111.

[14] Satish, S., Nagendra, H. and Ravi, G. (2012) Application of Remote Sensing and GIS for Flood Risk Analysis: A Case Study of Krishna and Tungabadra River Valley. International Journal of Social Science \& Interdiscilplinary Research, 1, 50-61.

[15] Helsel, D.R. and Hirsch, R.M. (2002) Statistical Methods in Water Resources: US Geological Survey Techniques of Water Resources Investigations, Book 4, Chap.

[16] Rowinski, P.M., Strupczewski, W.G. and Singh, V.P. (2002) A Note on the Applicability of Log-Gumbel and Log-Logistic Probability Distributions in Hydrological Analyses: I. Known pdf. Hydrological Sciences Journal, 47, 107-122. https://doi.org/10.1080/02626660209492911

[17] Dewan, A.M., Kumamoto, T. and Nishigaki, M. (2006) Flood Hazard Delineation in Greater Dhaka, Bangladesh Using an Integrated GIS and Remote Sensing Approach. Geocarto International, 21, 33-38. https://doi.org/10.1080/10106040608542381

[18] Bhatt, G.D., Sinha, K., Deka, P.K. and Kumar, A. (2014) Flood Hazard and Risk Assessment in Chamoli District, Uttarakhand Using Satellite Remote Sensing and GIS Techniques. International Journal of Innovative Research in Science, Engineering and Technology, 3, 9. https://doi.org/10.15680/IJIRSET.2014.0308039

[19] Ahmad, B., Muhammad, S.K., Butt, M.J. and Dahri, Z.H. (2010) Hydrological Modelling and Flood Hazard Mapping of Nullah Lai. Proceedings of the Pakistan Academy of Sciences, 47, 215-226.

[20] Sun, P., Wang, S., Gan, H., Liu, B. and Jia, L. (2017) Application of HEC-RAS for Flood Forecasting in Perched River-A Case Study of Hilly Region, China. IOP 
Conference Series: Earth and Environmental Science, 61, Article ID: 012067. https://doi.org/10.1088/1755-1315/61/1/012067

[21] Solaimani, K. (2011) GIS-Based Multidate Flood Forecasting Using Hydraulic Model. International Journal of Physical Sciences, 6, 577-582.

[22] Johnson, C.A., Yung, A.C., Nixon, K.R. and Legates, D.R. (2001) The Use of HEC-GeoHMS and HEC-HMS to Perform Grid-Based Hydrologic Analysis of a Watershed. Dodson \& Associates, Houston.

[23] Che, D. and Mays, L.W. (2015) Development of an Optimization/Simulation Model for Real-Time Flood-Control Operation of River-Reservoirs Systems. Water Resources Management, 29, 3987-4005. https://doi.org/10.1007/s11269-015-1041-8

[24] Feldman, A.D. (2000) Hydrologic Modeling System HEC-HMS: Technical Reference Manual. US Army Corps of Engineers, Hydrologic Engineering Center.

[25] Horritt, M.S. and Bates, P.D. (2002) Evaluation of 1D and 2D Numerical Models for Predicting River Flood Inundation. Journal of Hydrology, 268, 87-99. https://doi.org/10.1016/S0022-1694(02)00121-X

[26] Khattak, M., Anwar, F., Sheraz, K., Saeed, T., Sharif, M. and Ahmed, A. (2016) Floodplain Mapping Using HEC-RAS and ArcGIS: A Case Study of Kabul River. Arabian Journal for Science \& Engineering, 41, 1375-1390. https://doi.org/10.1007/s13369-015-1915-3

[27] Raaijmakers, R., Krywkow, J. and van der Veen, A. (2008) Flood Risk Perceptions and Spatial Multi-Criteria Analysis: An Exploratory Research for Hazard Mitigation. Natural Hazards, 46, 307-322. https://doi.org/10.1007/s11069-007-9189-Z

[28] Breton, C. and Marche, C. (2001) Decision Support for the Choice of Interventions in a Flood Zone. Journal of Water Science, 14, 363-379. https://doi.org/10.7202/705424ar

[29] Iosub, M., Enea, A., Hapciuc, O.E., Romanescu, G. and Minea, I. (2014) Flood Risk Assessment for the Ozana River Sector Corresponding to Leghin Village (Romania). 14th SGEM GeoConference on Water Resources Forest, Marine and Ocean Ecosystems, 19-25 June 2014, Vol. 1, 315-322. https://doi.org/10.5593/SGEM2014/B31/S12.041

[30] De Bruijn, K.M., Klijn, F., Pas, B. and Slager, C.T.J. (2015) Flood Fatality Hazard and Flood Damage Hazard: Combining Multiple Hazard Characteristics into Meaningful Maps for Spatial Planning. Natural Hazards and Earth System Sciences, 15, 1297-1309. https://doi.org/10.5194/nhess-15-1297-2015

[31] Meng, S., Xie, X. and Liang, S. (2017) Assimilation of Soil Moisture and Streamflow Observations to Improve Flood Forecasting with Considering Runoff Routing Lags. Journal of Hydrology, 550, 568-579. https://doi.org/10.1016/j.jhydrol.2017.05.024

[32] Arnal, L., Ramos, M.H., de Perez, E.C., Cloke, H.L., Stephens, E., Wetterhall, F. and Pappenberger, F. (2016) Willingness-to-Pay for a Probabilistic Flood Forecast: A Risk-Based Decision-Making Game. Hydrology and Earth System Sciences, 20, 3109-3128. https://doi.org/10.5194/hess-20-3109-2016

[33] Liu, L., Gao, C., Xuan, W. and Xu, Y.P. (2017) Evaluation of Medium-Range Ensemble Flood Forecasting Based on Calibration Strategies and Ensemble Methods in Lanjiang Basin, Southeast China. Journal of Hydrology, 554, 233-250. https://doi.org/10.1016/j.jhydrol.2017.08.032

[34] Uddin, K., Gurung, D.R., Giriraj, A. and Shrestha, B. (2013) Application of Remote Sensing and GIS for Flood Hazard Management: A Case Study from Sindh Province, Pakistan. American Journal of Geographic Information System, 2, 1-5. 